\title{
Extreme precipitation events over Saudi Arabia during the wet season and their associated teleconnections
}

\author{
Rana Muhammad Atif ${ }^{a, *}$, Mansour Almazroui ${ }^{\mathrm{a}}$, Sajjad Saeed ${ }^{\mathrm{a}, \mathrm{b}}$, Muhammad Adnan Abid ${ }^{\mathrm{a}, \mathrm{c}}$, \\ M. Nazrul Islam ${ }^{\mathrm{a}}$, Muhammad Ismail ${ }^{\mathrm{a}}$ \\ ${ }^{a}$ Center of Excellence for Climate Change Research (CECCR), Department of Meteorology, King Abdulaziz University, Jeddah, Saudi Arabia \\ ${ }^{\mathrm{b}}$ Department of Earth and Environmental Sciences, University of Leuven (KU Leuven), Belgium \\ ${ }^{\mathrm{c}}$ Earth System Physics Section, International Centre for Theoretical Physics (ICTP), Trieste, Italy
}

\section{A R T I C L E I N F O}

\section{Keywords:}

Extreme precipitation events (EPEs)

CGT

ENSO

Saudi Arabia

Arabian Peninsula

\begin{abstract}
A B S T R A C T
An assessment of the Extreme Precipitation Events (EPEs) is important because of their potential impacts on the local livelihood, ecosystem, and water resource management. In the present study, the EPEs are defined by applying a non-parametric $\left(95^{\text {th }}\right.$ percentile) approach over different climatic regions of Saudi Arabia using observed daily precipitation data for the period 1984-2016 obtained from 27 meteorological stations. The frequency, composite and correlation analyses are performed to evaluate the statistics of EPEs and their teleconnections. During the wet season (Nov-Apr), the frequency of the EPEs ( $\geq 25 \mathrm{~mm} /$ day) are higher over northeastern, central and southwestern coastal parts of Saudi Arabia. The composites and correlation analyses show that the EPEs over Saudi Arabia are associated with mid-latitude circumglobal wave train (CGT), which evolves a few days before the onset of EPEs and decays afterwards. The CGT modulates the upper-level trough over the Arabian Peninsula (AP) along with the surface anomalous low-pressure system that enhances moisture convergence, favoring the occurrence of EPEs over the region. The EPEs over Saudi Arabia are also associated with El Niño Southern Oscillation (ENSO), which shows that during the positive (negative) ENSO phase the frequency of EPEs increases (decreases) over the country. Moreover, the El Niño (with positive CGT) enhances the EPEs frequency over Saudi Arabia while vice-versa happens for La Niña (with negative CGT) phase.
\end{abstract}

\section{Introduction}

An extreme precipitation event (EPE) may be defined as an intense precipitation event that rarely occurs at a particular region any time of the year bringing the catastrophic conditions to the regional socioeconomic sector (Beniston and Stephenson, 2004). The EPEs are mainly associated with flash floods, dust storms, cyclones, which significantly influence the society. In recent period, the probability of occurrence of the EPEs has increased many folds over different regions in particular over wet-tropics and mid-latitudes, in the wake of future climate change (Alexander et al., 2006; IPCC, 2007; Seneviratne et al., 2012; Donat et al., 2013, 2014). Saudi Arabia is a semi-arid region, in which southwestern region receives most rainfall in summer (June-September) season, while north and northeast regions receive rainfall during the wet (November-April) season (Almazroui, 2011a, 2012; Almazroui et al., 2012a; Almazroui et al., 2012b; Almazroui et al., 2013). The country has experienced more EPEs in recent decades, which caused flash flooding in different regions, among these most noticeable are in November 2009, December 2010 and January 2011. Due to these events, many casualties and billions of dollars of loss to the regional infrastructure are reported (EM-DAT, C., 2012; Elquliti et al., 2016). Although, few case studies have been conducted to explore the underlying mechanism associated with EPEs over Saudi Arabia (de Vries et al., 2013, 2018; Haggag and El-Badry, 2013; Deng et al., 2015). However, the EPEs variability and their relationship with the largescale forcings that modulate them over Saudi Arabia is yet unknown, which is investigated in the present study by using the observed station and reanalysis datasets.

It is imperative to study the phenomena that can influence the occurrence of EPEs (Shimizu et al., 2017). The large-scale atmospheric phenomena such as El Niño Southern Oscillation (ENSO), and Circumglobal Wave Train (CGT) are known to have significant influence over the occurrence and shifting of EPEs over the different regions of northern hemisphere (Gershunov and Barnett, 1998; Branstator, 2002;

\footnotetext{
* Corresponding author at: Center of Excellence for Climate Change Research (CECCR), Department of Meteorology, King Abdulaziz University, P.O.Box 80208, Jeddah 21589, Saudi Arabia.

E-mail address: rsattar@stu.kau.edu.sa (R.M. Atif).
} 


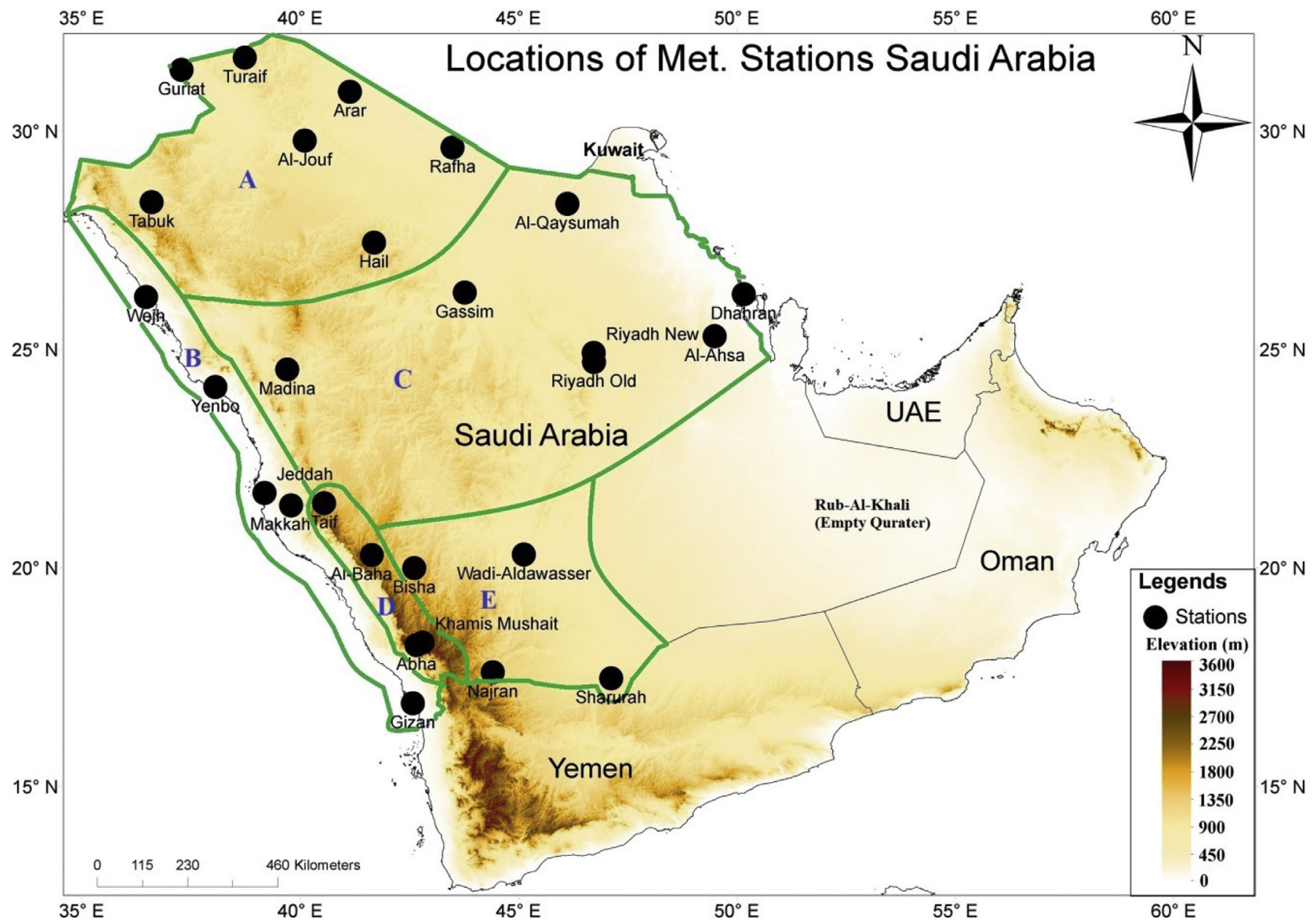

Fig. 1. Locations of meteorological stations in Saudi Arabia (black dots). The legend indicates the elevations of the different meteorological stations. Five climatic zones are segregated by the green line $(\mathrm{A}=$ Northern, $\mathrm{B}=$ Red Sea Coast, $\mathrm{C}=$ Interior, $\mathrm{D}=$ Highland, and $\mathrm{E}=$ Southern). (For interpretation of the references to colour in this figure legend, the reader is referred to the web version of this article.)

Ding and Wang, 2005; Ding and Wang, 2007; Feldstein and Dayan, 2008; Casanueva et al., 2014; Agel et al., 2015; Wei et al., 2017). The ENSO is the coupled-ocean atmospheric phenomenon that occurs in the central-eastern equatorial Pacific Ocean, which tends to affect the seasonal rainfall variability and predictability around the globe (e.g. Rasmusson and Carpenter, 1983; Ropelewski and Halpert, 1987; Kucharski et al., 2007; Yadav et al., 2010; Kang et al., 2015; Kucharski and Abid, 2017; Abid et al., 2018; Kamil et al., 2019; and others). The ENSO may bring more EPEs over the regions, where it has a positive relationship (Seneviratne et al., 2012). The EPEs are non-linear, they may occur in all ENSO phases, but their frequency and intensity may vary from one phase to another (Higgins et al., 2000; Sun et al., 2015). For example, the regional EPEs of North America during the wintertime are found to be significantly associated with ENSO phases (Gershunov and Barnett, 1998; Cayan et al., 1999; DeFlorio et al., 2013). On the other hand, the ENSO has the negative relationship with the amount and frequency of EPEs over South America as the EPEs pattern shifts from northwest to southeast during an El Niño phase and vice versa (Grimm and Tedeschi, 2009). Recent studies show that ENSO modulates the wet season rainfall through the subtropical jet stream. During the warm ENSO phase subtropical jet shifts southwards from its mean location, which increases the mid-latitude storms frequency over the Arabian Peninsula (AP) and thus more rainfall during wet season, while vice-versa happens in the cold ENSO phase (Kang et al., 2015; Niranjan Kumar et al., 2015; Abid et al., 2016; Kamil et al., 2017). This may increase the EPEs frequency over the region during the ENSO period, which is not well studied.

The CGT is another mode of variability that influences the precipitation and mid-latitude frontal systems in the northern hemisphere (Branstator, 2002). The CGT is defined as low-frequency disturbances, which are meridionally trapped and zonally elongated in the mid-latitude region along the vicinity of the subtropical jet stream, generating a wave-like pattern. The CGT wave-like pattern has strong potential to influence the mid-latitude seasonal rainfall and circulation patterns in the northern hemisphere (Ding and Wang, 2005; Feldstein and Dayan, 2008; Saeed et al., 2011, 2014; Wei et al., 2017; de Vries et al., 2018; Saeed and Almazroui, 2019). Saeed and Almazroui (2019) have shown that CGT strongly influences regional rainfall over the Arabian Peninsula in particular over Saudi Arabia. They also have shown that CGT is different from that of North Atlantic Oscillation (NAO), where NAO has insignificant relationship with the AP rainfall particularly over Saudi Arabia, which is also discussed by Ehsan et al. (2017). This indicates that CGT may also modulate the EPEs in the region, which is discussed in the current study.

In the present study, we are analyzing the frequency of EPEs over Saudi Arabia during the wet season in relationship with ENSO and CGT phenomena. Furthermore, we also analyzed the ENSO influence on the CGT that may modulate the EPEs over Saudi Arabia, which is yet not known. We examined the frequency distribution of the EPEs over different climatic zones of Saudi Arabia by using observed station dataset. The findings will contribute to knowledge and understanding of EPEs occurrence over Saudi Arabia, which will ultimately help to devise 
Table 1

Names, locations, and elevations of the meteorological stations used in the study. The five regions covering Saudi Arabia are defined following Almazroui et al. (2015).

\begin{tabular}{|c|c|c|c|c|c|}
\hline Sr. No. & Met. stations & Latitude $\left({ }^{\circ} \mathrm{N}\right)$ & Longitude $\left({ }^{\circ} \mathrm{E}\right)$ & Elevation (m) & Region \\
\hline 1 & AlJouf & 29.78 & 40.1 & 670 & Northern (A) \\
\hline 2 & Arar & 30.9 & 41.14 & 550 & \\
\hline 3 & Gurait & 31.4 & 37.28 & 504 & \\
\hline 4 & Hail & 27.44 & 41.69 & 1000 & \\
\hline 5 & Rafha & 29.62 & 43.49 & 445 & \\
\hline 6 & Tabuk & 28.37 & 36.6 & 770 & \\
\hline 7 & Turaif & 31.68 & 38.73 & 852 & \\
\hline 8 & Gizan & 16.9 & 42.58 & 4 & Red Sea Coast (B) \\
\hline 9 & Jeddah & 21.71 & 39.18 & 18 & \\
\hline 10 & Makkah & 21.43 & 39.79 & 273 & \\
\hline 11 & Wejh & 26.2 & 36.47 & 20 & \\
\hline 12 & Yenbo & 24.14 & 38.06 & 8 & \\
\hline 13 & AlAhsa & 25.3 & 49.49 & 180 & Interior (C) \\
\hline 14 & AlQaysumah & 28.33 & 46.12 & 360 & \\
\hline 15 & Dhahran & 26.26 & 50.16 & 22 & \\
\hline 16 & Gassim & 26.3 & 43.77 & 648 & \\
\hline 17 & Madinah & 24.54 & 39.7 & 630 & \\
\hline 18 & Riyadh New & 24.92 & 46.72 & 612 & \\
\hline 19 & Riyadh Old & 24.71 & 46.73 & 610 & \\
\hline 20 & Abha & 18.23 & 42.66 & 2100 & Highland (D) \\
\hline 21 & AlBaha & 20.29 & 41.64 & 1655 & \\
\hline 22 & Khamis Mushait & 18.29 & 42.8 & 2047 & \\
\hline 23 & Taif & 21.48 & 40.55 & 1455 & \\
\hline 24 & Bisha & 19.99 & 42.61 & 1167 & Southern (E) \\
\hline 25 & Najran & 17.61 & 44.41 & 1213 & \\
\hline 26 & Sharurah & 17.47 & 47.12 & 727 & \\
\hline 27 & Wadi-Aldawasser & 20.3 & 45.12 & 617 & \\
\hline
\end{tabular}

adaptation strategies for weather, and seasonal forecasting, agricultural and disaster management practices in the region. The paper is organized as follows: Section 2 presents information about the data and methodology used in this study. Section 3 elaborates the results and discussion while Section 4 describes the conclusions.

\section{Datasets and methodology}

\subsection{Datasets}

In the current study, daily station precipitation dataset, obtained from the General Authority of Meteorology and Environmental Protection (GAMEP) for 27 meteorological observatories across Saudi Arabia (Fig. 1, Table 1) for the period 1984-2016, is utilized. The data was thoroughly checked for missing or any unexpected high values to ensure the continuity and homogeneity during the study period. We defined ENSO wet season index from monthly Sea Surface Temperature (SST) data for Tropical Pacific region called (Niño 3.4) available at National Oceanic and Atmospheric Administration Earth System and Research Laboratory (NOAA/ESRL by Physical Science Division (PSD)) website (https://www.esrl.noaa.gov/psd/gcos_wgsp/Timeseries/Data/ nino34.long.data). Similarly, the NAO wet season index was also defined using NAO index data obtained from (ftp://ftp.cpc.ncep.noaa. gov/cwlinks). The global daily reanalysis data for the variables Geopotential Heights (GPHs), meridional wind (V), zonal wind (U), specific humidity (q), and Mean Sea Level Pressure (MSLP) from European Centre for Medium-Range Weather Forecasts (ECMWF) Re-Analysis (ERA-Interim) at spatial resolution $0.75^{\circ} \times 0.75^{\circ}$ in longitude and latitude (Dee et al., 2011) have been used for the composite analysis of the identified EPEs over Saudi Arabia. For the precipitation composites, we have employed daily precipitation data from ERA-Interim at relatively higher spatial resolution $0.125^{\circ} \times 0.125^{\circ}$ in longitude and latitude. Moreover, daily Interpolated Outgoing Longwave Radiations (OLR) data (Liebmann and Smith, 1996) obtained from the NOAA/ESRL-PSD is also used for the OLR composite analysis. To find the spatial correlation between the frequency of EPEs over Saudi Arabia and ENSO, Extended Reconstructed Sea Surface Temperature (ERSST) Version-5 at spatial resolution of $2.0^{\circ} \times 2.0^{\circ}$ in longitude and latitude (Huang et al., 2017), provided by the NOAA/OAR/ESRL PSD, Boulder, Colorado, USA, has been used.

\subsection{Methodology}

\subsubsection{Definition of EPEs}

Different definitions have been adapted to study the EPEs in the different regions (e.g. Klein Tank and Können, 2003; Anagnostopoulou and Tolika, 2012; Alsarmi and Washington, 2014). For example, Klein Tank and Können (2003) and Anagnostopoulou and Tolika (2012) used the 99th percentile to define the threshold for the EPEs over the European region. Alsarmi and Washington (2014) studied the extreme precipitation indices developed by Expert Team on Climate Change Detection and Indices (ETCCDI) over the AP using daily precipitation data from 23 meteorological stations covering six countries and found weak and insignificant trends for the number of days with $>10 \mathrm{~mm}$ precipitation over the region. However, there is no study available on defining the EPE thresholds over Saudi Arabia and its climate zones using the observed precipitation dataset.

In this study, a non-parametric approach based on the $95^{\text {th }}$ percentile of the precipitation distribution has been employed for the identification of EPEs during the wet season over Saudi Arabia. The extreme daily precipitation event is defined as an event for which the accumulated daily precipitation from all the meteorological stations is equal to and above the $95^{\text {th }}$ percentile. The observed daily precipitation from each station was divided into different precipitation bin sizes (mm/day), and the combined frequency from all the stations in each bin size is presented in Fig. 2a. Later the percentages for each bin size were calculated with respect to the total precipitation events in all the bins. Finally, for the identification of EPEs, over whole Saudi Arabia and its climatic zones characterized by Almazroui et al. (2015), the threshold was selected based on the $95^{\text {th }}$ percentile values. The EPEs are counted for each wet season for the period 1984-2016 (i.e., total 32 years) where each season represents the total number of EPEs within that particular season. 
a) Rainfall Events Frequency Distribution over Saudi Arabia during Wet Season
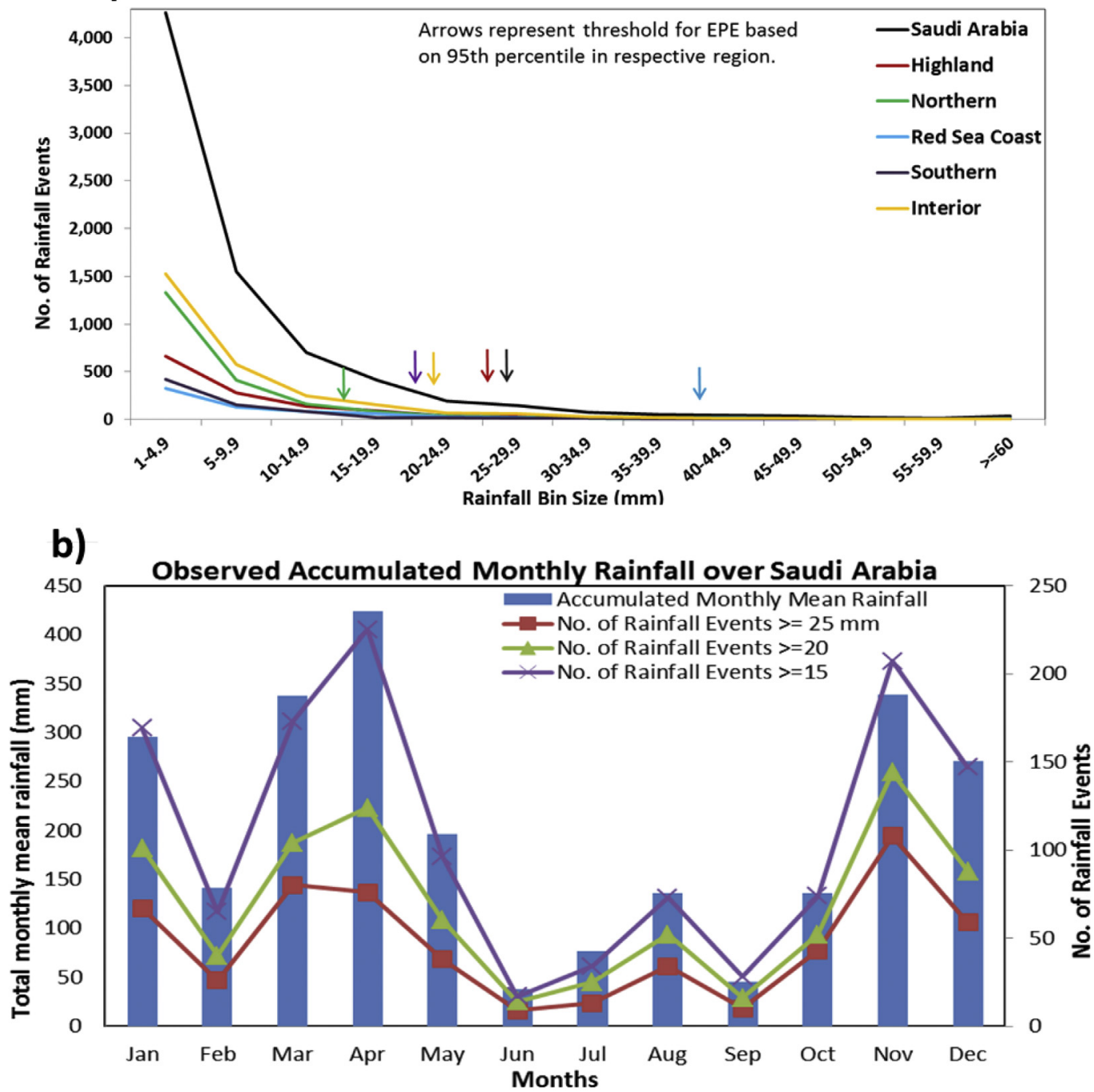

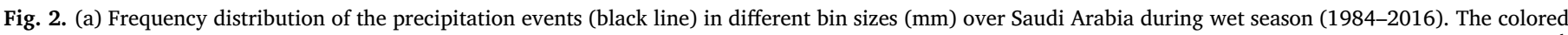

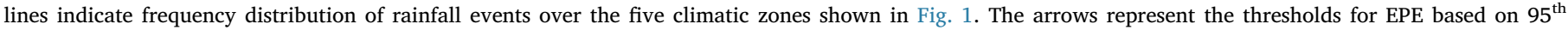

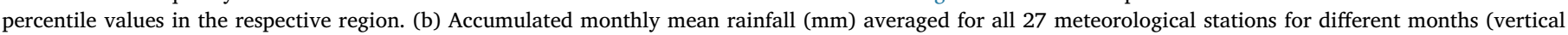

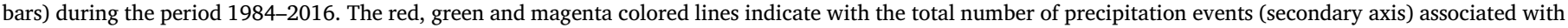
25,20 , and $15 \mathrm{~mm}$ respectively. (For interpretation of the references to colour in this figure legend, the reader is referred to the web version of this article.)

\subsubsection{Composite definition}

In order to analyze the atmospheric conditions during EPEs over Saudi Arabia, the composites are obtained for meridional wind (V), zonal wind (U) in the upper atmosphere (i.e. $200 \mathrm{hPa}$ ), GPHs at $500 \mathrm{hPa}$, wind vector $(\vec{u}, \vec{v})$ at $850 \mathrm{hPa}, \mathrm{MSLP}$, and Vertically Integrated Moisture Transport (VIMT) based on the reanalysis dataset. The composites in this study are defined by taking the difference between days with extreme events and the days without extreme events (hereafter the normal days) (Almazroui et al., 2018), as mentioned in the equation below;

COMP. $=\frac{1}{n} \sum_{i=1}^{n} X_{i}-\frac{1}{m} \sum_{j=1}^{m} X_{j}$

where $n$ and $m$ are the total number of extreme events days and the normal days respectively and $X$ is the variable under consideration. The composite analysis was carried out for all EPEs occurred during all years, as well as during ENSO (El Niño, La Niña and Neutral) phases. A $t$-test, where the unequal variance of the two samples is involved, is used for the composites (Weir, 1960; Abid et al., 2016).

\subsubsection{Lead-lag relationship}

The persistence of upper atmospheric conditions leading to the EPEs over Saudi Arabia was analyzed by the lead-lag composites for the GPHs at $500 \mathrm{hPa}$ with the days interval of $-15,-10,-05,-02,+02$, $+05,+10$, and +15 days before and after the EPEs occurrence. Although the life cycle of the anomalous wave-like pattern associated with CGT has -5 to +5 days interval during the winter season (Wang and Zhang, 2015). However, to understand the detail evolution of the wave-like pattern during the EPEs in wet season, we made the composites from -15 to +15 days.

\subsubsection{Association with large scale forcing}

The correlation analysis is used to identify the relationship between the EPEs over Saudi Arabia with a favorable surface and upper-level conditions. The wet season average precipitation and EPEs frequency are correlated with the Niño3.4, NAO and CGT indices. The CGT index was obtained by taking first Principal Component (PC1) associated with Empirical Orthogonal Function (EOF) analysis on the meridional winds at $200 \mathrm{hPa}$ within the domain $10^{\circ} \mathrm{W}-80^{\circ} \mathrm{E}, 15^{\circ}-45^{\circ} \mathrm{N}$ during the wet season. Furthermore, the frequency of EPEs over Saudi Arabia is also 

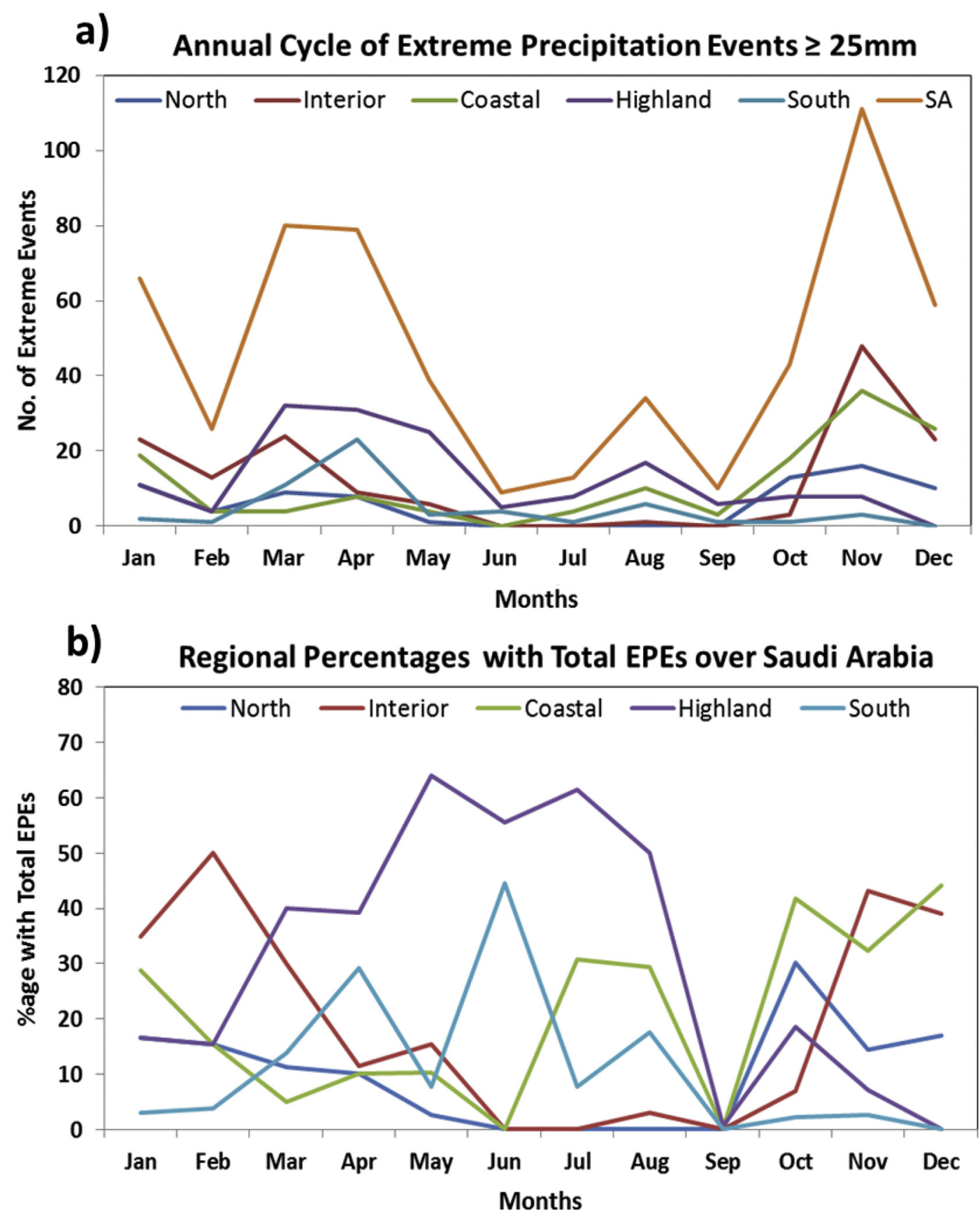

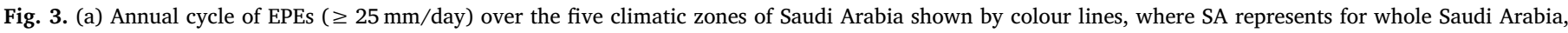

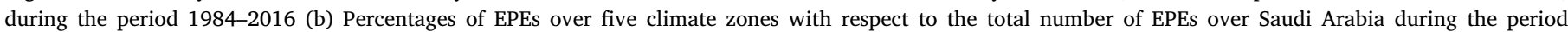
1984-2016.

correlated with global SSTs and GPHs at $200 \mathrm{hPa}$ to analyze the role of large scale forcing in its modulation. Finally, the t-test applied for the significance of the correlations.

The relevance of the obtained mid-latitude wave-like pattern associated with EPEs and the mid-latitude CGT was also checked with the help of EOF analysis. Two leading EOF modes, one obtained at our selected domain $\left(10^{\circ} \mathrm{W}-80^{\circ} \mathrm{E}, 15^{\circ}-45^{\circ} \mathrm{N}\right)$ and the other obtained within the domain $\left(0-120^{\circ} \mathrm{E}, 0-45^{\circ} \mathrm{N}\right)$ as defined by Branstator (2002), were compared. Both the leading EOF modes explain maximum variances and corresponding PC1 time series are well correlated with 0.96 correlation coefficient (statistically significant at $99 \%$ ). Therefore, we infer that the first EOF pattern from our selected domain as the regional manifestation of the CGT pattern.

Based upon the normalized PC1 time series, also known as CGT index, the years with $>0.5$, within \pm 0.5 , and $<-0.5$, values are defined as positive, neutral and negative CGT phases respectively. Similarly, ENSO phases are defined from the Niño3.4 wet season index as El Niño $\left(\geq 0.5^{\circ} \mathrm{C}\right.$ ), Neutral (hereafter neutral ENSO phase) (within $\pm 0.5^{\circ} \mathrm{C}$ ), and La Niña $\left(\leq-0.5^{\circ} \mathrm{C}\right)$ respectively. List of positive and negative CGT phases along with El Niño and La Niña years are shown in Table 3.

\subsubsection{Moisture transport}

The vertically integrated moisture fluxes may lead to the anomalous distribution of the EPEs (Gimeno et al., 2016). For example, Zolina et al. (2016) identify that the strong interannual variability of the moisture transport from the Red Sea significantly affects the precipitation of the AP and northeastern African regions. Therefore, the VIMT was 


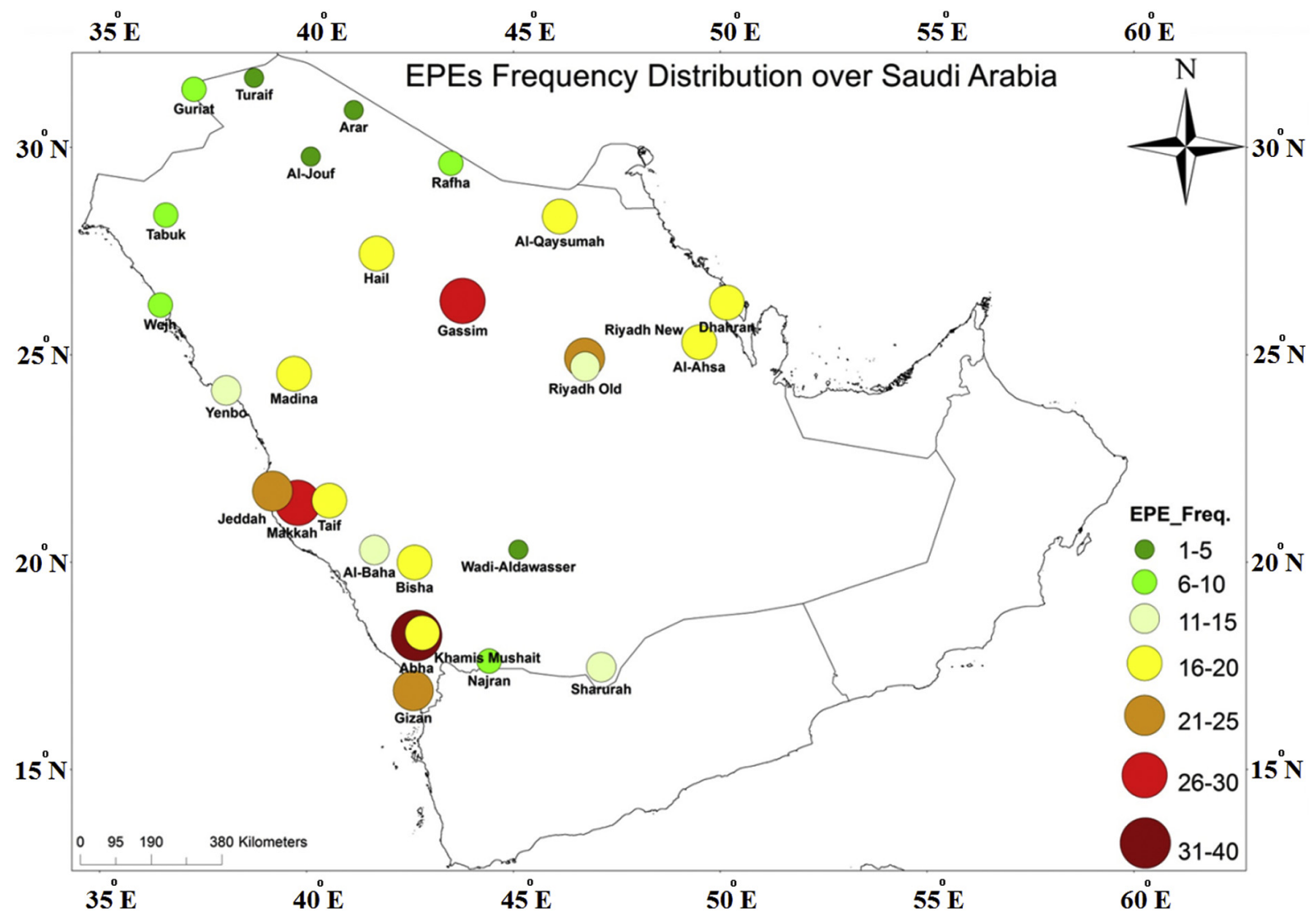

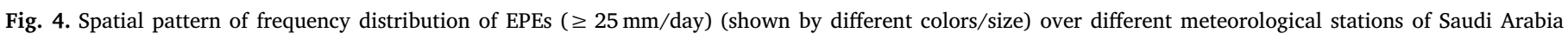
during the wet season (Nov-Apr) for the period 1984-2016.

calculated using Eq. (2) and (3) from the surface $\left(\mathrm{P}_{s}\right)$ to $700 \mathrm{hPa}\left(\mathrm{P}_{u}\right)$ (Lélé et al., 2015).

$\overline{Q_{u}}=\frac{1}{\mathrm{~g}} \int_{P u}^{P s} \overline{q u} d P$

$\overline{Q_{v}}=\frac{1}{\mathrm{~g}} \int_{P u}^{P s} \overline{q v} d P$

where $\overline{Q_{u}}$ and $\overline{Q_{v}}$ are the zonal and meridional components of the vertically integrated total mean water vapor flux respectively $(\mathrm{kg}$. $\left.\mathrm{m}^{-1} \mathrm{~s}^{-1}\right)$, " $g$ " is the acceleration due to gravity with value $9.8 \mathrm{~m} . \mathrm{s}^{-2}$, " $q$ " represents the specific humidity $(\mathrm{Kg} / \mathrm{Kg}), \vec{u}$ and $\vec{v}$ are the zonal and meridional wind components $(\mathrm{m} / \mathrm{s})$ respectively. Moreover, the moisture fluxes and moisture convergence/divergence are analyzed during El Niño and La Niña phases using the composite difference between El Niño minus neutral ENSO phase (EL-Neutral) and La Niña minus neutral ENSO phase (LN-Neutral).

\section{Results and discussion}

\subsection{Observed statistics of the EPEs over Saudi Arabia}

Fig. 1 shows the location of the meteorological stations used in this study. The different climate zones within Saudi Arabia i.e., the Interior, Southern, Highland, Red Sea Coast, and Northern regions, respectively are segregated by the green line (Almazroui et al., 2015). Based on $95^{\text {th }}$ percentile method, the threshold values of precipitation amount used to define the extreme events are 25, 20, 20, 25, 40, and $15 \mathrm{~mm}$ /day for entire country, Interior, Southern, Highland, Red Sea Coast, and Northern regions, respectively and are represented by the colored arrows in Fig. 2a.

The accumulated monthly precipitation averaged over Saudi Arabia for the study period is shown in Fig. 2b. The maximum (minimum) precipitation occurs in April (June), amounting to $423.18 \mathrm{~mm}$ $(38.24 \mathrm{~mm})$, after aggregating precipitation over all stations and averaging over the duration (1984-2016). Higher frequency of precipitation events in lower thresholds values (i.e., up to $15 \mathrm{~mm}$ /day) is observed over Saudi Arabia during April, as shown in Fig. 2b (magenta line). However, considering EPEs threshold ( $\geq 25 \mathrm{~mm} /$ day), Saudi Arabia receives more EPEs in November followed by March and April. There are also few EPEs occurred in October and May, which are marked as transition months between wet and dry season, as discussed by Almazroui et al. (2015). February is a relatively drier month during the wet season with fewer numbers of EPEs. Overall, the accumulated monthly mean precipitation pattern is indicative that most of the precipitation occurs due to western disturbances during winter and spring season with less dominance of South Asian Monsoon over Saudi Arabia during the study period, consistent with the findings of Athar (2015). Moreover, the characteristic of precipitation is entirely different between winter and dry season. The southern/southwestern part of the country receives precipitation during the dry season due to easterly jet, which brings moisture into the region, and topography plays an important role in yielding precipitation over the region (Almazroui, 2011b; Almazroui et al., 2013).

We analyze the annual cycle of EPEs frequency over Saudi Arabia as presented in Fig. 3a, which clearly indicates that the Interior and Red Sea Coast regions receive more EPEs during November as compared with other regions. From March-September, the distribution of EPEs shows enhanced frequency over the Highland region. Red Sea Coast region starts receiving extreme events from October and the percentages of EPEs occurrence remain high, as compared with other regions, till February (Fig. 3b). The EPEs are very rare during the months of June and September over Saudi Arabia. Although Highland and Southern regions have very few EPEs during the month of June 

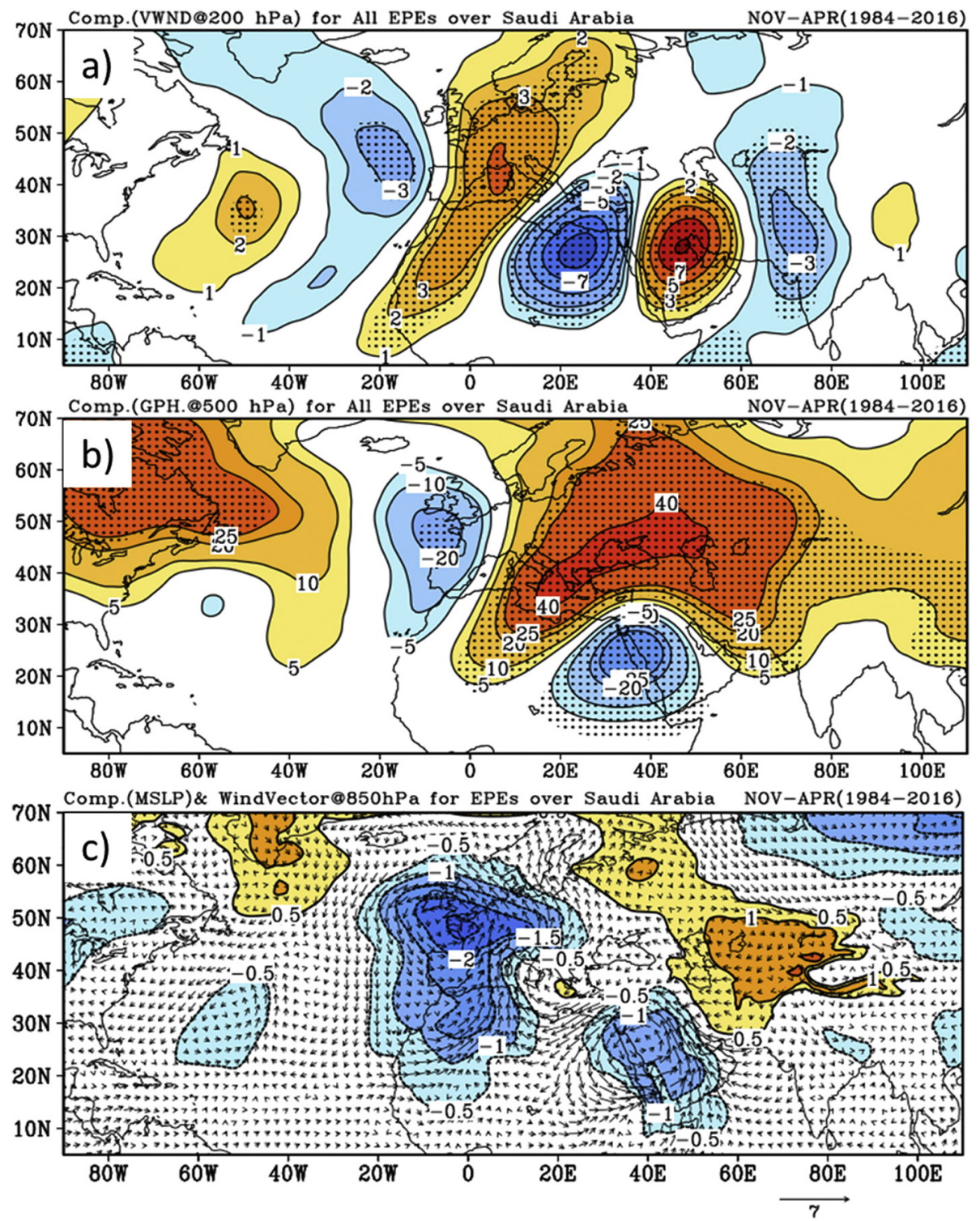

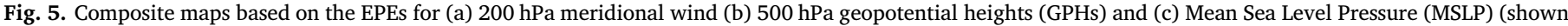

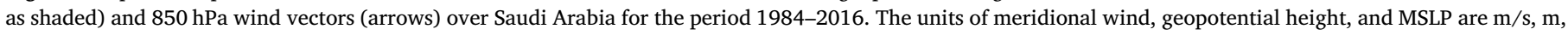
and $\mathrm{hPa}$ respectively. The statistical significance at $99 \%$ based on t-test is shown as stipples.

however, September is the only month in which all the regions show near to zero percentages of EPEs. Fig. 4 shows the spatial distribution for the frequency of EPEs over Saudi Arabia during the wet season from 1984 to 2016. The highest number of EPEs is reported over Abha (Highland) followed by Makkah (Red Sea Coast) and Gassim (Interior). The distribution shows that EPEs are also more frequent over Jeddah, Gizan, and Riyadh (New) as compared with rest of the stations. However, stations from northern and southern regions show the lowest occurrence of EPEs except Hail and Bisha, in respective regions, where there are relatively higher EPEs during the period. Overall, the frequency pattern indicates that most of the EPEs occur in southwestern Red Sea Coast, Highland, and northeastern Interior regions of the country during the period. One of the possible local factors affecting the frequency of EPEs in each region is the elevation of each station in that region. The stations with highest reported EPEs in each region are the most elevated stations in their respective regions except Bisha (second highest elevated station in the southern region). For example, Hail, Makkah, Gassim, and Abha with the highest number of reported EPEs are the most elevated stations in Northern, Red Sea Coast, Interior, and Highland regions respectively (Fig. 4, Table 1).

\subsection{EPEs association with CGT}

Fig. 5 shows the composite maps based on EPEs and the normal days. The composites for meridional wind at $200 \mathrm{hPa}$ and GPHs at $500 \mathrm{hPa}$, shown in Fig. 5a, b respectively, reveal a wave-like pattern in the mid-latitude associated with the EPEs over Saudi Arabia. This wavelike pattern in the upper atmospheric level has resemblance with the CGT wave pattern already identified by the previous studies (e.g. Branstator, 2002; Ding and Wang, 2005; Saeed et al., 2011, 2014; Almazroui et al., 2019). This CGT pattern extends eastward from North Atlantic Ocean toward Europe and South Asia is likely to affect the precipitation of the region (Watanabe, 2004). The CGT pattern modulates the mid-latitude cyclone activity (Wang et al., 2013; Wang and Zhang, 2015) which brings cold air in the upper troposphere over AP including Saudi Arabia during the wet season. Further, the CGT pattern also facilitates upper air divergence through the jet stream, which helps to develop the Mesoscale Convective Systems (MCS) as discussed by Branstator (2002).

The composite for MSLP shows the presence of anomalous surface low pressure, which extends from southwest to the northeast of the AP 

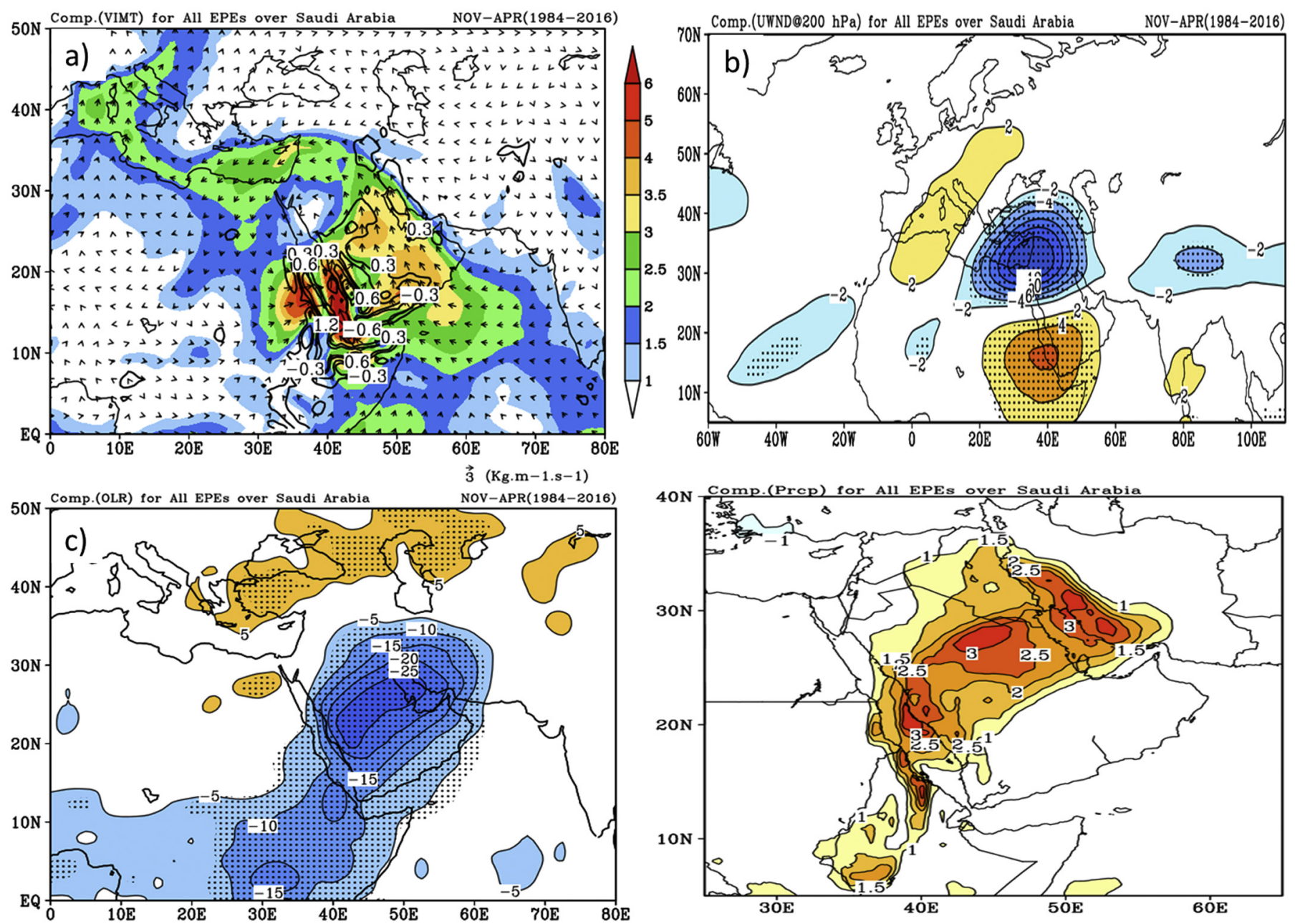

Fig. 6. Composite maps of (a) mean Vertically Integrated Moisture Transport (VIMT) moisture flux (shaded for magnitude and vectors for direction) (unit: $\mathrm{Kg} \cdot \mathrm{m}^{-1} \cdot \mathrm{s}^{-1}$ ) integrated from surface- $700 \mathrm{hPa}$ and moisture convergence/divergence (contours) (unit: $10^{-5} \mathrm{Kg} \cdot \mathrm{m}^{-2} \cdot \mathrm{s}^{-1}$ ) the positive contour values show the convergence while negative values show the divergence, (b) $200 \mathrm{hPa}$ zonal wind (unit: $\mathrm{m} / \mathrm{s}$ ) depicting the position and intensity of the jet stream (c) Outgoing Long Wave Radiation (OLR) (unit: $\mathrm{W} / \mathrm{m}^{2}$ ). Blue and brown shaded regions show the negative and positive OLR values respectively, (d) Precipitation (unit: $\mathrm{mm}$ ), based on the EPEs over Saudi Arabia for the period 1984-2016. The statistical significance at $99 \%$ based on $t$-test is shown as stipples. (For interpretation of the references to colour in this figure legend, the reader is referred to the web version of this article.)

region (Fig. 5c). The anomalous surface low pressure and its associated trough, also known as Red Sea trough, has an essential role in yielding EPEs over the AP region (e.g Tsvieli and Zangvil, 2007; Krichak et al., 2012; de Vries et al., 2013; Almazroui et al., 2016). This surface low pressure provides favorable conditions in bringing warm moist air into the region from the Red Sea and the Arabian Sea, which is also evident in the composite of wind vector at $850 \mathrm{hPa}$ (Fig. 5c). Composite for the VIMT total mean water vapor flux further bolsters this evidence that a considerable amount of moisture was transferred and converged over Saudi Arabia from these two moisture sources mentioned above during these events (Fig. 6a). Moreover, it is revealed that the eastern Mediterranean Sea is also a weak source of the moisture for the EPEs over Saudi Arabia. The result is consistent with the findings of de Vries et al., 2013, who investigated the moisture dynamics for the EPEs over AP and Levant region associated with the Red Sea trough. When the upper tropospheric trough accompanies the Red Sea trough, the warm moist air tends to cause unstable atmosphere leading to the development of MCS over the region (Krichak et al., 2012; Almazroui et al., 2016). In addition, the elevated topography of the southwestern mountainous region also contributes to uplift this moisture to provide the convective instability in the region.

The CGT pattern expects to enhance the jet stream activity and exerts increased positive vorticity to facilitate upper air divergence (de
Vries et al., 2018; Wang and Wang, 2018). The upper-level divergence plays a crucial role in the formation of MCS in the presence of low level warm and moist air. Anomaly composite of zonal wind at $200 \mathrm{hPa}$ during the EPEs over Saudi Arabia clearly indicates the presence of the subtropical jet stream over AP region (Fig. 6b). It is further supported by the OLR anomaly for the EPEs over Saudi Arabia (Fig. 6c), which shows the presence of strong convective system (i.e. MCS) and could favor more precipitation. Fig. $6 \mathrm{~d}$ shows the positive precipitation anomalies over northeastern, central and southwestern Red Sea Coastal regions of the country, which may result in more EPEs in the region. Therefore, the position of the jet stream in association with CGT plays a significant role in the occurrence of the EPEs over Saudi Arabia.

The evolution and recession of the CGT pattern before and after the onset of EPEs is shown in Fig. 7a-h by using the EPE anomaly composites defined in Eq. (1). Zonal atmospheric flow can be seen over AP region fifteen days before the EPEs as shown in Fig. 7a. Atmospheric reshaping begins as a strong negative GPHs anomaly at $500 \mathrm{hPa}$ starts appearing over the Atlantic Ocean ten days before the occurrence of EPEs over Saudi Arabia (Fig. 7b). The anomalies dipole further strengthens up to five days before the occurrence of EPEs shown in Fig. 7c. Another negative anomaly evolves over the AP and adjoining African region two days before the EPEs which continues to strengthen with time over the region (Fig. 7d) and reaches to its full mature stage 

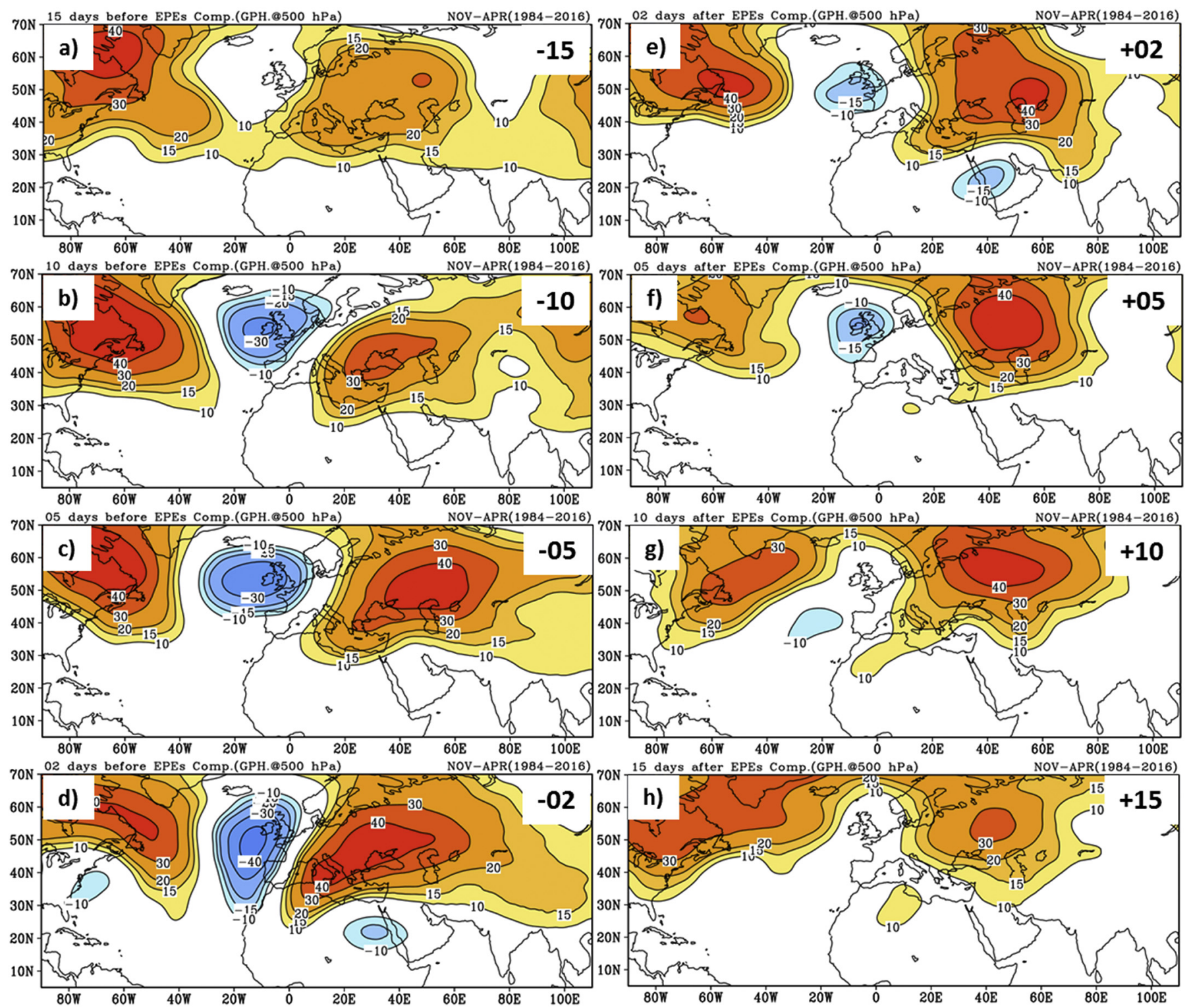

Fig. 7. Lead-Lag composites of geopotential heights at $500 \mathrm{hPa}$ before and after the occurrence of EPEs over Saudi Arabia (a-h) with interval $-15,-10,-05,-02$, $+02,+05,+10$ and +15 days respectively. The lead lag days are shown in the upper right corner of each plot.

Table 2

The correlation coefficients of observed average precipitation and the number of EPEs $\geq 25 \mathrm{~mm}$ over Saudi Arabia, with global indices during wet season (1984-2016). The * sign represents 95\% statistical significance of correlations based on $t$-test.

\begin{tabular}{llll}
\hline Variable & Niño3.4 & CGT & NAO \\
\hline Average precipitation & $0.36^{*}$ & $0.41^{*}$ & -0.1 \\
EPEs frequency & $0.30^{*}$ & $0.29^{*}$ & -0.03 \\
\hline
\end{tabular}

on the days of EPEs (Fig. 5b). The CGT pattern starts weakening gradually after the EPEs as shown in Fig. 7e-h and completely vanishes after five days of EPEs (Fig. 7f) and onward. These results further support the findings of Feldstein and Dayan (2008), who found that this CGT teleconnection pattern has a life span of seven days with maximum amplitude on the day and significant decay after 5 days of EPEs. From the above discussion, we noticed that the mid-latitude CGT influences the upper-level anomalous trough and surface low-pressure systems over AP, which in turn favors the EPEs over the region.

\subsection{Teleconnections associated with EPEs}

We examined the relationship between the wet seasonal mean precipitation over Saudi Arabia with the large scale forcings (ENSO, CGT, and NAO) by using correlation analysis as shown in Table 2 . The Correlation Coefficient (CC) between the seasonal mean precipitation and the ENSO is 0.36 , while with CGT is 0.41 , which is statistically significant at the $95 \%$ level. However, insignificant (CC $=-0.1$ ) is noticed between NAO and seasonal mean precipitation, which is consistent with the findings of Ehsan et al. (2017) and Saeed and Almazroui, 2019. This shows that seasonal mean precipitation is significantly influenced by the ENSO and CGT, which may modulate EPEs over Saudi Arabia. Therefore, from now onwards, we focussed only on the interannual variability of EPEs frequency in relationship with ENSO and CGT as shown in Fig. 8.

Fig. 8a shows the EPEs interannual variability in relationship with standardized Niño3.4 and CGT indices during the wet season of the study period. The significant CC of 0.3 and 0.29 are found with ENSO and CGT respectively, which are statistically significant at the $90 \%$ level. The spatial distribution of the CC between the EPEs frequency 

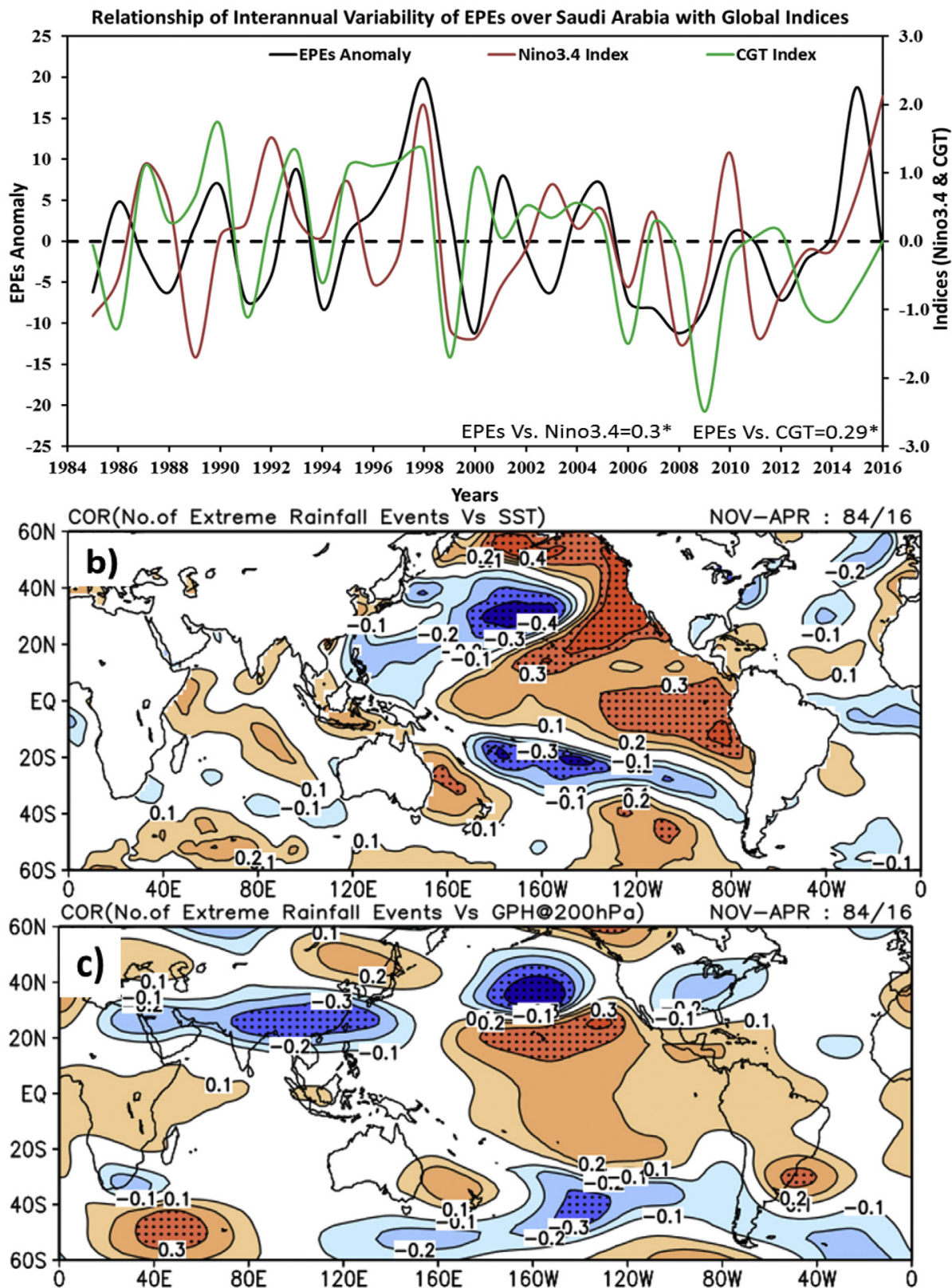

Fig. 8. (a) Interannual variability of the wet season EPEs for the period 1984-2016 over Saudi Arabia (Black line). Standardized Niño3.4 SST index (red line) and CGT Index (green line) are shown by secondary axis. The correlation numbers are shown in the bottom where $\left(^{*}\right)$ represents the significance of correlation at $95 \%$ level (b) Map of spatial correlation coefficients between the wet season EPEs and global SSTs (c) Map of spatial correlation between EPEs and GPHs at $200 \mathrm{hPa}$ during wet season over Saudi Arabia for the period 1984-2016. The stipples show the regions where correlations are significant to $95 \%$ based on t-test. (For interpretation of the references to colour in this figure legend, the reader is referred to the web version of this article.)
Table 3

List of positive and negative phases of CGT and ENSO Years, defined on the bases of respective indices during wet season of the study period. The * sign represents the wettest years with the highest number of EPEs.

\begin{tabular}{ll}
\hline Phases & Years \\
\hline Positive CGT & $1986,1988,1989,1992,1994,1995,1996,1997^{*}, 1999,2001,2003$ \\
Negative CGT & $1985,1990,1993,1998,2004,2005,2008,2012,2013,2014^{*}$ \\
El Niño & $1986,1987,1991,1994,1997^{*}, 2002,2004,2009,2014^{*}, 2015$ \\
La Niña & $1984,1988,1995,1998,1999,2000,2005,2007,2008,2010,2011$ \\
\hline
\end{tabular}

and global SSTs, as well as with GPHs at $200 \mathrm{hPa}$ for the study period are presented in Fig. 8b, c, respectively. The results reveal that EPEs have reasonable correlation ranging between 0.3 and 0.4 with $95 \%$ significance level with the SSTs of the eastern equatorial and northern Pacific Ocean, including ENSO region (Fig. 8b). A negative correlation of -0.3 to-0.2, of EPEs with $200 \mathrm{hPa}$ GPHs can be seen over the AP region extending from China (Fig. 8c), while positive correlation is noticed in the Pacific region, which is consistent with the earlier studies
(Kang et al., 2015; Abid et al., 2016; Ehsan et al., 2017). Therefore, ENSO may provide background state for the occurrence of EPEs over Saudi Arabia.

The observed statistics of EPEs over Saudi Arabia and its climatic regions is shown in Table 4. About $44.6 \%$ of the EPEs occur over Saudi Arabia during the positive CGT phase (Table 4). While $31.5 \%$ of the EPEs frequency is noted in negative CGT phase, and $23.9 \%$ occurs in the neural CGT phase. The results are in line with the findings of Feldstein and Dayan (2008), where they have discussed that winter precipitation between the eastern Mediterranean and north of AP enhances during the positive CGT phase, and vice versa. From the above discussion, we infer that the EPEs over Saudi Arabia are related with the CGT phases with enhanced (reduced) frequency during the positive (negative) phase. Similarly, frequency of EPEs over Saudi Arabia and its climatic regions during ENSO phases is presented in Table 5. It reveals that although, the EPEs occur during all phases of ENSO, however, overall frequency is higher during El Niño phase. It is noticed that overall about $37.4 \%, 36.3 \%$, and $26.3 \%$ of the EPEs over Saudi Arabia occur during El Niño, Neutral and La Niña ENSO phases respectively. Although, a 
Table 4

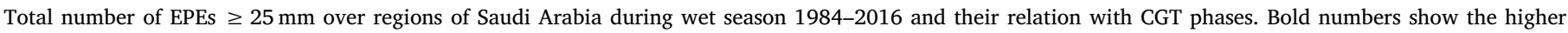
percentages in the respective region.

\begin{tabular}{|c|c|c|c|c|c|c|c|}
\hline Regions & EPEs & Positive CGT & Neutral CGT & Negative CGT & $\%$ Positive CGT & $\%$ Neutral CGT & $\%$ Negative CGT \\
\hline Northern & 58 & 15 & 17 & 26 & 25.86 & 29.31 & 44.83 \\
\hline Red Sea Coast & 97 & 40 & 31 & 26 & 41.24 & 31.96 & 26.80 \\
\hline Interior & 140 & 67 & 29 & 44 & 47.86 & 20.71 & 31.43 \\
\hline Highland & 87 & 51 & 10 & 26 & 58.62 & 11.49 & 29.89 \\
\hline Southern & 40 & 15 & 14 & 11 & 37.50 & 35.0 & 27.5 \\
\hline Overall & 422 & 188 & 101 & 133 & 44.55 & 23.93 & 31.52 \\
\hline
\end{tabular}

Table 5

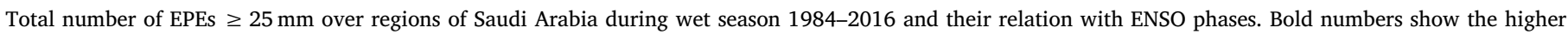
percentages in the respective region.

\begin{tabular}{|c|c|c|c|c|c|c|c|}
\hline Regions & EPEs & El Niño & Neutral & La Niña & \% El Niño & $\%$ Neutral & \%La Niña \\
\hline Northern & 58 & 26 & 18 & 14 & 44.83 & 31.03 & 24.14 \\
\hline Red Sea Coast & 97 & 33 & 39 & 25 & 34.02 & 40.21 & 25.77 \\
\hline Interior & 140 & 57 & 43 & 40 & 40.71 & 30.71 & 28.57 \\
\hline Highland & 87 & 23 & 43 & 21 & 26.44 & 49.43 & 24.14 \\
\hline Southern & 40 & 19 & 10 & 11 & 47.50 & 25.0 & 27.50 \\
\hline Overall & 422 & 158 & 153 & 111 & 37.44 & 36.26 & 26.30 \\
\hline
\end{tabular}

Table 6

EPEs Percentages during CGT phases in relation with ENSO phases over regions of Saudi Arabia during wet season 1984-2016. Bold numbers show the higher percentages in the respective region.

\begin{tabular}{|c|c|c|}
\hline \multirow[t]{2}{*}{ Region } & El Niño & La Niña \\
\hline & $\%$ + VE CGT & $\%-$ VE CGT \\
\hline Northern & 19.23 & 21.43 \\
\hline Red Sea Coast & 27.27 & 16 \\
\hline Interior & 47.37 & 30 \\
\hline Highland & 52.17 & 33.33 \\
\hline Southern & 31.58 & 27.27 \\
\hline
\end{tabular}

significant number of EPEs occur in neutral phase, which shows that there may be some other large scale factors influencing EPEs that will be explored in subsequent studies. Therefore, the EPEs statistics are discussed only in extreme ENSO phases.

The link between CGT and ENSO during the wet season is established by the SST anomaly composites shown in the positive and negative CGT phases respectively in Fig. 9(a, b). During positive CGT phase, the warm SSTs anomalies (i.e., El Niño phase) in the central and eastern Pacific region (Fig. 9a) are noted while negative SST anomalies (i.e., La Niña phase) are found in the negative CGT phase (Fig. 9b). Moreover, we found a modest CC of 0.25 between ENSO and CGT indices, which shows that ENSO may modulate CGT during the wet season. This indicates that a positive (negative) CGT phase is likely to
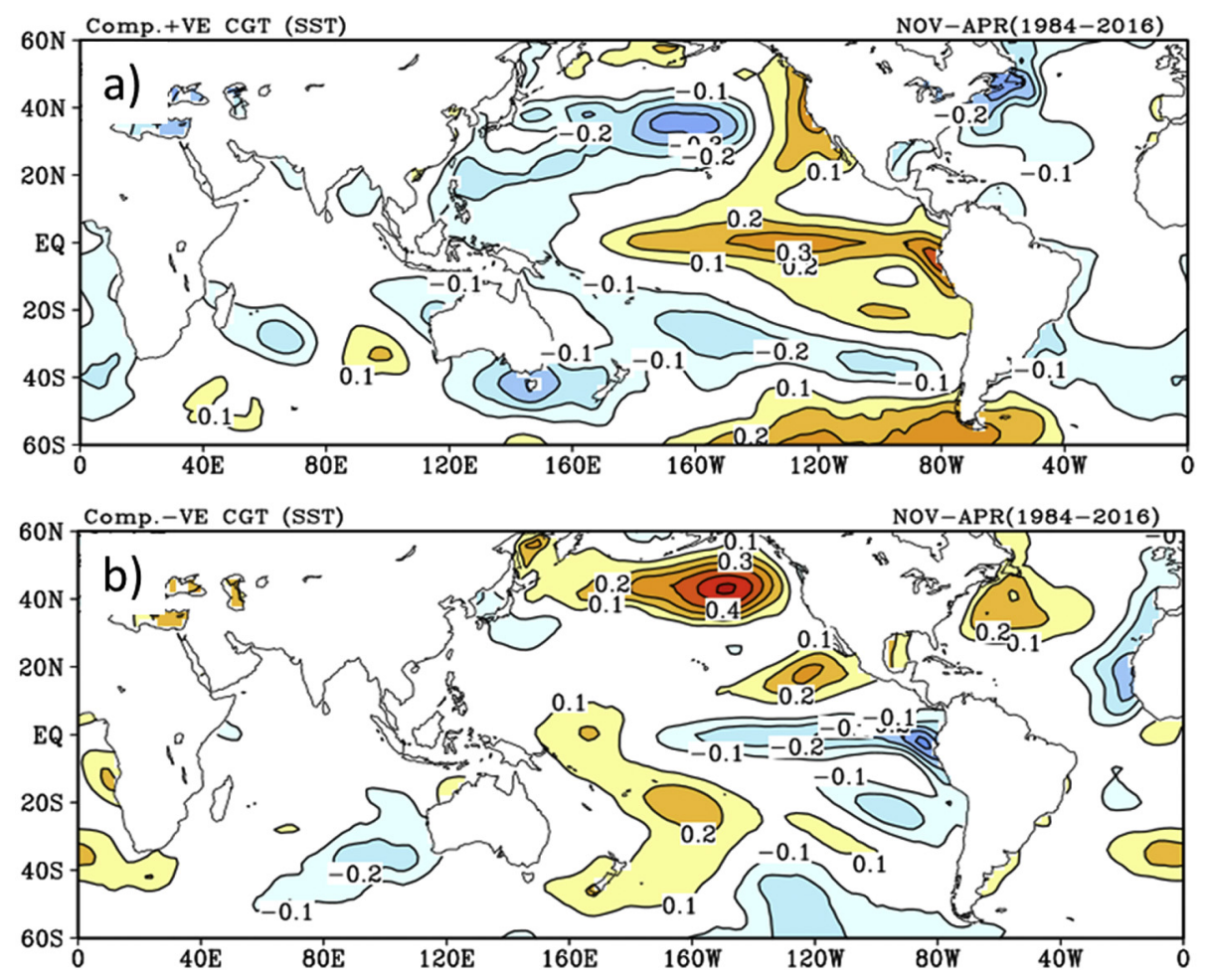

Fig. 9. Composites of the Sea Surface Temperature (SST) based on CGT phases during (a) positive CGT phase, and (b) negative CGT phase. 

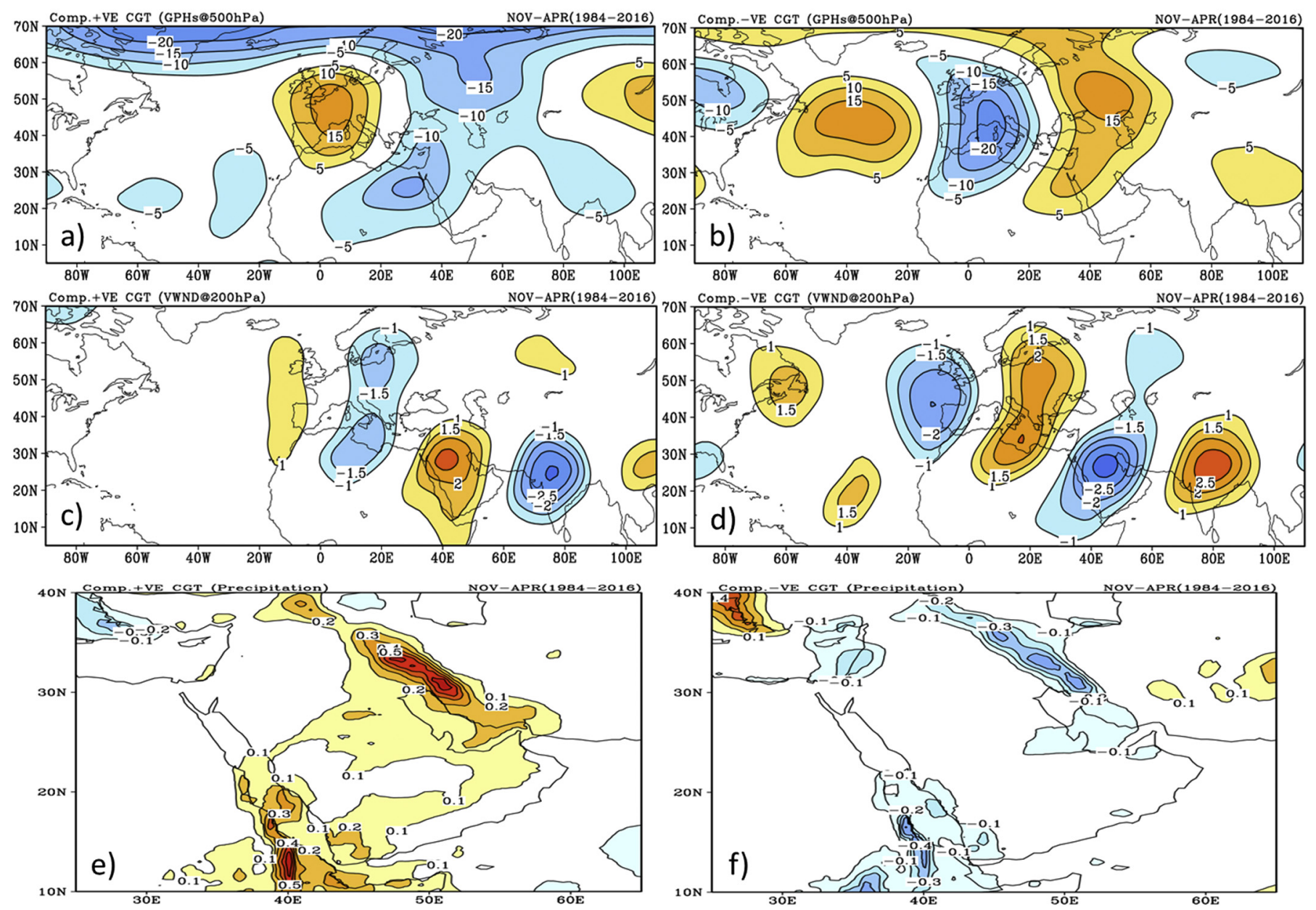

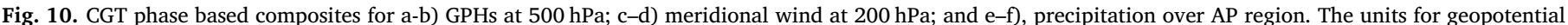
heights, meridional wind and precipitation are $\mathrm{m}, \mathrm{m} / \mathrm{s}$ and $\mathrm{mm}$ respectively.

be forced by the warm (cold) ENSO phase. This link between the ENSO and CGT is further explored by defining the composite of $500 \mathrm{hPa}$ geopotential height anomalies, the $200 \mathrm{hPa}$ meridional wind anomalies, and the precipitation anomalies based on the CGT phases. The positive CGT phase tends to force the negative GPHs anomalies at $500 \mathrm{hPa}$ over Eastern Mediterranean and AP region (Fig. 10a) and vice-versa in the negative CGT phase as shown in Fig. 10(b). The anomalous negative GPHs during this phase are further associated with positive meridional wind circulations at $200 \mathrm{hPa}$ (Fig. 10c) over the region which favor the mid-latitude storm's activities through cold air advection. However, during negative CGT phase the positive GPHs and negative meridional wind anomalies are witnessed (Fig. 10b, d), which suppress the midlatitude storm's activity and thus the rainfall in the region. Due to this anomalous upper-level atmospheric behavior, the resulting precipitation composites over the AP and adjacent regions show the above normal rainfall in the positive phase, while negative precipitation anomalies are noted in the negative CGT phase as shown by Fig. 10e, $\mathrm{f}$ respectively. This shows that during warm ENSO and positive CGT phase, the AP region may experience more EPEs, and vice-versa in the cold ENSO phase. Therefore, next we analyzed EPEs composites during the different ENSO phases.

Fig. 11(a-b) shows the composites of the GPHs at $500 \mathrm{hPa}$, for the EPEs over Saudi Arabia during extreme ENSO phases (i.e., El Niño and La Niña). Fig. 11 (a) shows relatively stronger CGT pattern at $500 \mathrm{hPa}$ GPHs anomalies with a southward shift over the north and northeastern region, that may bring more rainfall and thus may increase the EPEs frequency in the region during El Niño compared to that of total shown in Fig. 5b, which is consistent with earlier findings (e.g., Kang et al.,
2015; Abid et al., 2016). During La Niña, the weakening of the CGT is noted (Fig. 11b), with northward shift of the pattern to the AP, compared to that of Fig. 5b. The positive GPHs anomalies appear over Eastern Europe, and the Mediterranean Sea are weakened, which affects the storm tracks and reduces EPEs during La Niña phase as discussed by Kamil et al. (2017).

Moreover, the composites of the moisture flux along with moisture convergence are also calculated for the EPEs during El Niño, La Niña and neutral phases. However, for the difference among the El Niño and La Niña phases, we are showing the composite difference of (El NiñoNeutral) and La Niña -Neutral phase in Fig. 12(a,b) respectively. The difference for moisture flux and convergence shows the enhanced moisture and convergence at low level over the AP region from the Arabian Sea to Saudi Arabia in particular over the central, northern and northeastern regions during the El Niño phase (Fig. 12a). This may favor the upper-level trough providing suitable conditions for convection and thus precipitation in the region as discussed by Saeed and Almazroui (2019). Comparativley less moisture flux and convergence are noticed during the La Niña composite (La Niña-Neutral) difference from the Arabian Sea over the Saudi Arabia (Fig. 12b), which may attribute to the reduced frequency of EPEs over all the climate regions of Saudi Arabia. However, the incursion of the moisture to the northern and northeastern parts of the country is relatively higher as shown (Fig. 12a), which may favor more EPEs in this region during El Niño phase. Likewise, a prominent CGT pattern can also be seen from the composites of meridional wind at $200 \mathrm{hPa}$ for EPEs during different ENSO phases as shown in (Fig. S1). Therefore, more EPEs are expected during warm ENSO and positive CGT phase in comparison to the cold 

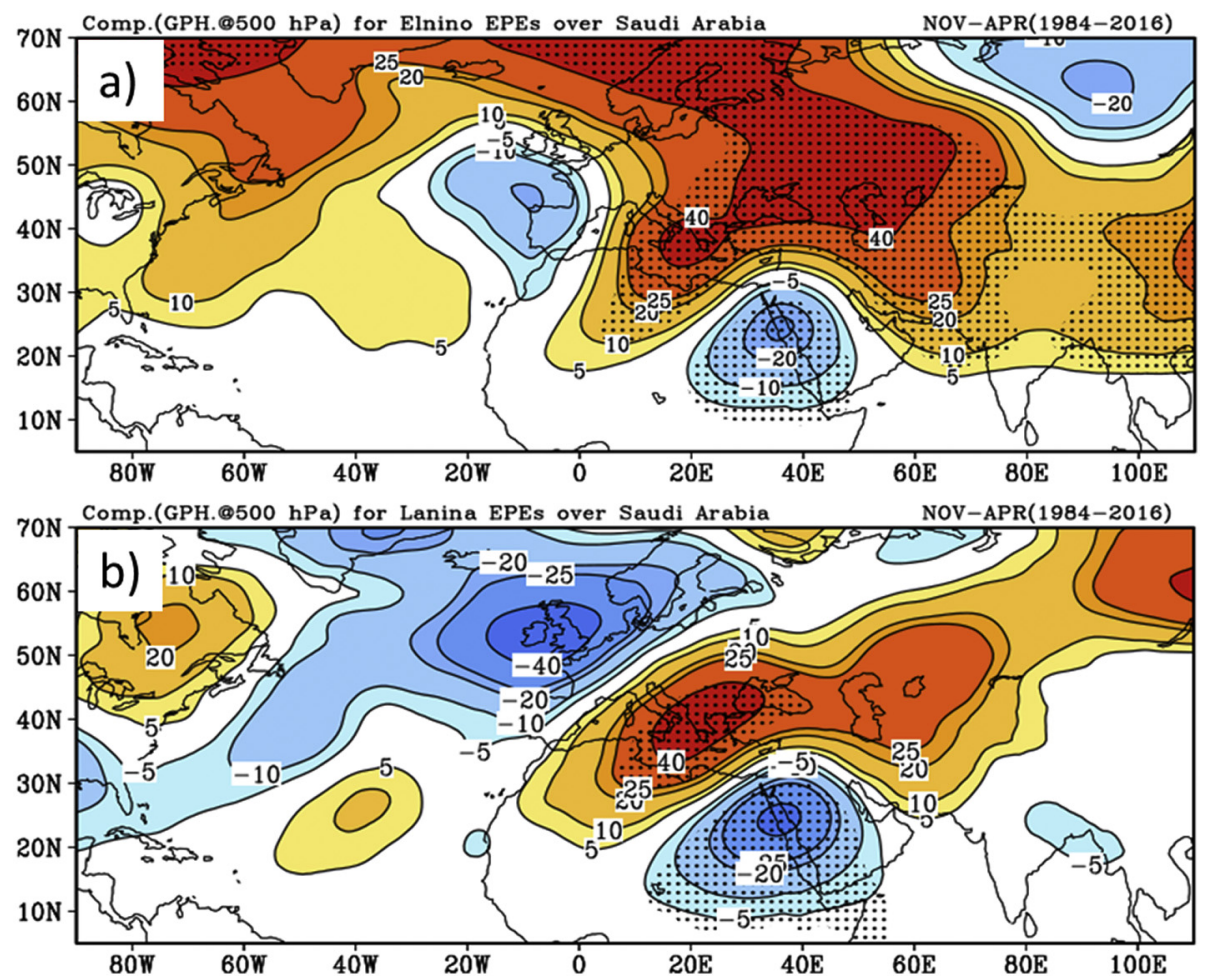

Fig. 11. Composites for $500 \mathrm{hPa}$ GPHs based on EPEs over Saudi Arabia during (a) El Niño Years (b) La Niña Years. The unit of geopotential height is m. The statistical significance at $99 \%$ based on t-test is shown as stipples.
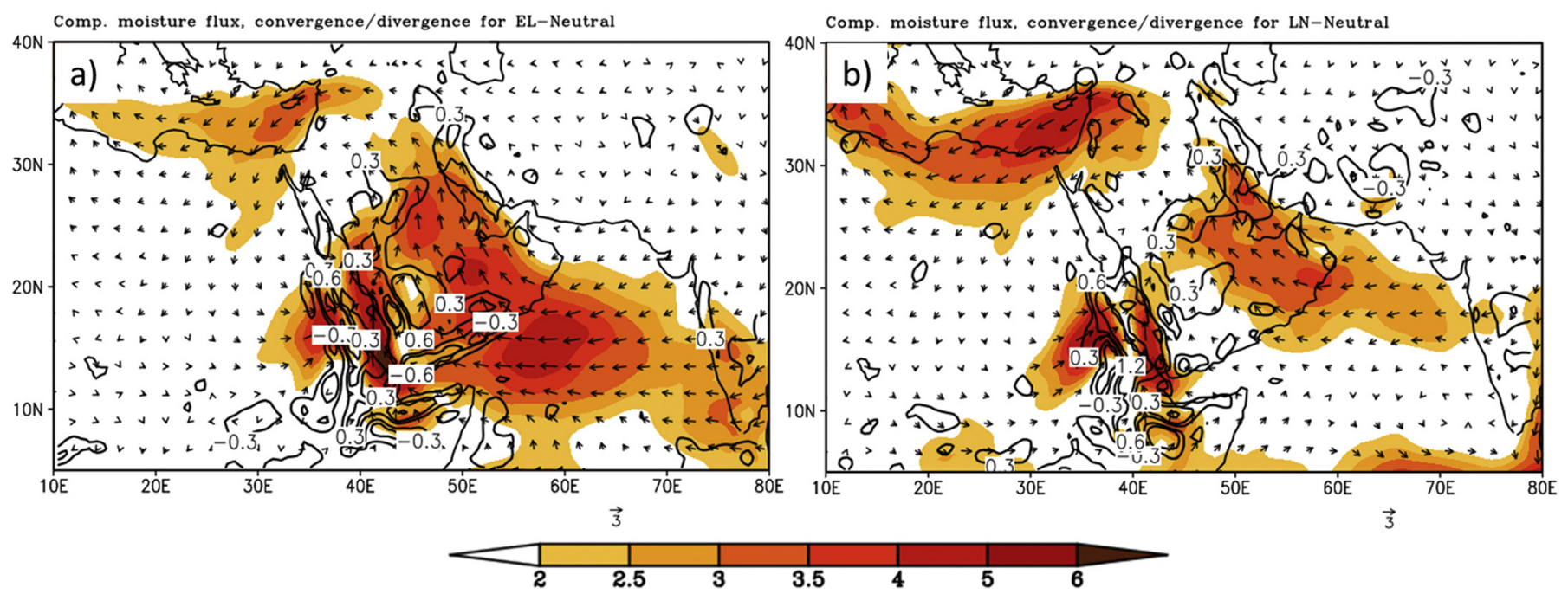

Fig. 12. Composite difference of mean Vertically Integrated Moisture Transport (VIMT) moisture flux (shaded for magnitude and vectors for direction) (unit: $\mathrm{Kg} \cdot \mathrm{m}^{-1} \cdot \mathrm{s}^{-1}$ ) integrated from surface-700 hPa and moisture convergence/divergence (contours) (unit: $10^{-5} \mathrm{Kg} \cdot \mathrm{m}^{-2} \cdot \mathrm{s}^{-1}$ ) based on EPEs over Saudi Arabia during (a) El Niño-Neutral phase (b) La Niña-Neutral phase. The positive contour values show the convergence while negative values show the divergence.

ENSO and negative CGT phases. We quantified the EPEs for each station and discussed in the next section.

\subsection{Distribution of EPEs over Saudi Arabia during ENSO phases}

We noticed that CGT, ENSO and their combined response tend to influence the EPEs frequency over the Saudi Arabia. Therefore, the EPEs frequency for each station are categorized during the warm, cold ENSO without considering CGT phases as shown in Fig. 13(a, b) respectively. As ENSO and CGT are positively correlated, therefore, we also characterized the EPEs in their respective phases, i.e., warm ENSO (positive CGT), cold ENSO (negative CGT) phase as shown in Fig. 13(c, d) respectively. During El Niño phase, Saudi Arabia receives more EPEs compared to that of La Niña phase in the wet season (Fig. 13a, b). The frequency of the EPEs is pronounced over several stations in Interior, Southern, Highland and Red Sea Coastal regions, where it is higher compared to the other climatic zones, which is consistent with the findings of Abid et al. (2016). However, during La Niña (Fig. 13b), the frequency of EPEs is significantly less over most of Saudi Arabia, which favors the dry conditions that tend to modulate more dust storm activity over the northern AP as discussed by Almazroui et al. (2018). Furthermore, it is interesting to note that during the El Niño phase, most of the EPEs occurred when there was positive CGT phase as shown in Fig. 13c. For example, during El Niño phase, the stations like 

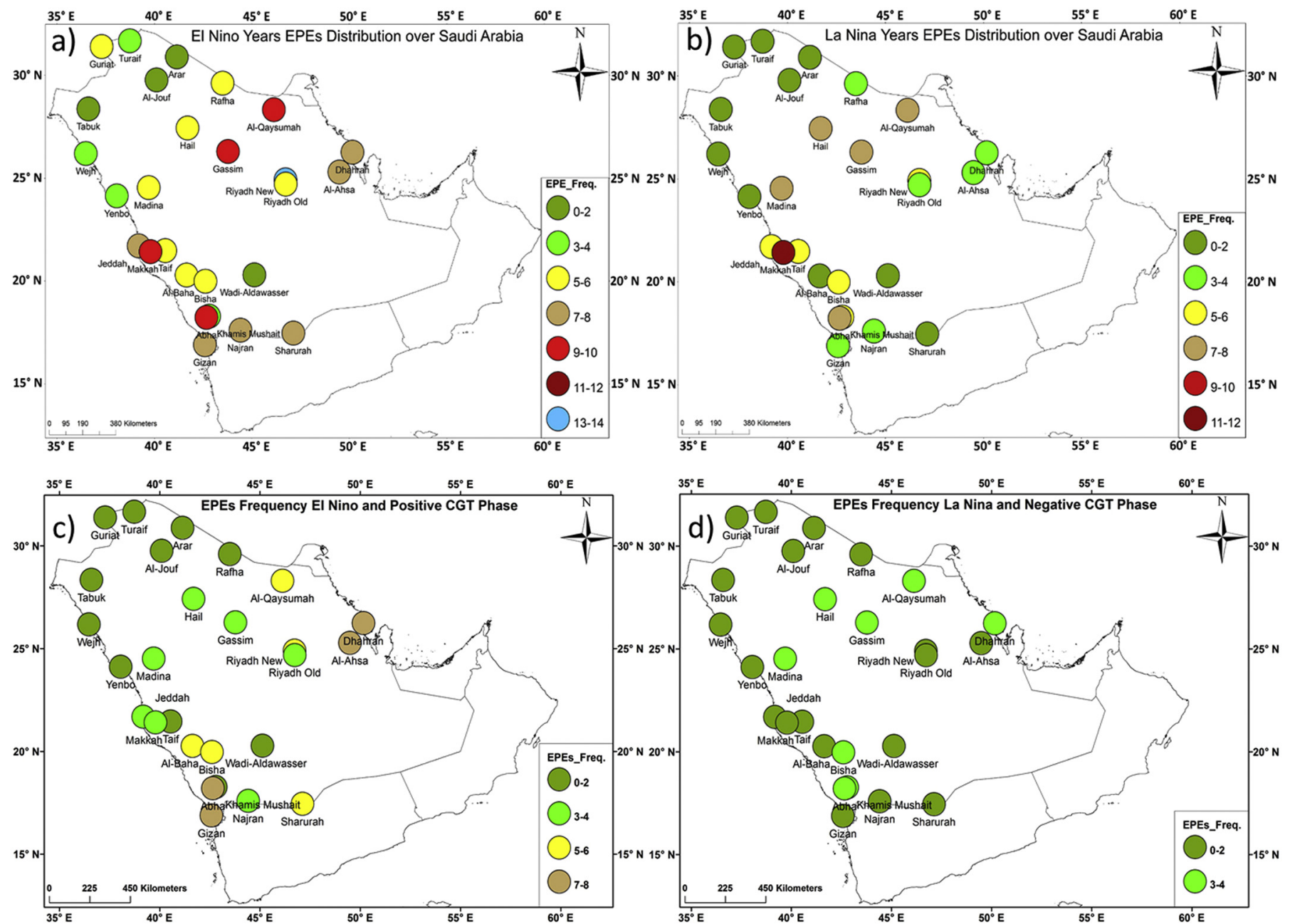

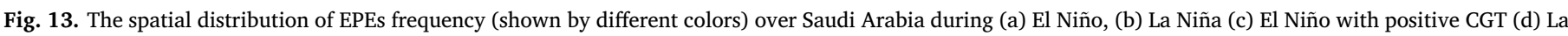
Niña with negative CGT phases.

Dhahran, AlAhsa, Riyadh (new), AlQaysumah (Interior region) shows that mostly EPEs occur when both ENSO and CGT are in their positive phases (Fig. 13c). Therefore, the combined effect of El Niño and positive CGT favors the increase of the EPEs frequency over Saudi Arabia. However, during La Niña and negative CGT, only $27 \%$ of the events occurred (Fig. 13d) compared to the total EPEs in La Niña phase (Fig. 13b). The detailed observed statistics of EPEs over regions of Saudi Arabia during El Niño (positive CGT) and La Niña (negative CGT) is presented in Table 6. Therefore, it is concluded that EPEs frequency significantly increases over most of the stations when ENSO and CGT are in a warm and positive phase respectively, while it decreases vice versa. This is also consistent with the precipitation composites shown in extreme CGT phases (Fig. 10e, f). This information based on the ENSO and CGT is useful for the prediction of the EPEs over the Saudi Arabia.

\section{Summary and conclusions}

In this study, we investigated the frequency of daily extreme precipitation events (EPEs) over Saudi Arabia during the wet season (NovApril) using observed station and reanalysis datasets. The events above $95^{\text {th }}$ percentile over different climatic zones of Saudi Arabia are defined as EPEs. The threshold for the different climatic zones was inhomogeneous, but in the present study, we considered a single/homogeneous threshold for entire Saudi Arabia $(25 \mathrm{~mm} /$ day $)$, the annual cycle of EPEs shows that Interior and Red Sea Coast regions receive more EPEs during the month of November and December compared to other regions. Whereas, the Highland and Southern regions receive more EPEs from March to September. Overall, the observed frequency of EPEs is higher over northeastern, central and southwestern coastal parts of Saudi Arabia during the wet season 1984-2016.

The wet seasonal EPEs over Saudi Arabia are modulated by the midlatitude circumglobal wave train (CGT). The presence of CGT wavelike pattern enhances the mid-latitude cyclone activity, which is further responsible for bringing upper air cold wind over Saudi Arabia. Moreover, the CGT favors the upper-level divergence through the jet stream, which helps to develop the Mesoscale Convective System (MCS) over the country. The anomalous surface low pressure in the lower troposphere over Saudi Arabia assists the warm and moist air from the two main water sources, i.e. the Red Sea and the Arabian Sea during the EPEs. Hence, the CGT and its associated upper-level trough above the western AP, and the anomalous surface low pressure bringing significant moisture flux are the key players to initiate the EPEs over Saudi Arabia. The evolution of the CGT like pattern begins 10 days before the EPEs when negative GPHs anomalies at $500 \mathrm{hPa}$ appear over the northern Atlantic Ocean, initiate the EPEs over Saudi Arabia. These negative anomalies continue to strengthen while another negative GPHs anomalies center at $500 \mathrm{hPa}$ appear over the AP two days before the occurrence of EPEs. The CGT pattern shows its full maturity on the day of EPEs and starts decaying immediately and disappears after five days of the occurrence of EPEs.

We found that the ENSO and CGT mainly influence the interannual variability of the EPEs. A positive correlation of 0.30 and 0.29 for the 
wet season EPEs of Saudi Arabia with the Niño 3.4 and CGT is noted respectively, which is statistically significant at the $90 \%$ level. This shows that the positive ENSO and CGT phase tends to enhance the EPEs over Saudi Arabia and vice-versa for the negative phases. Observed statistics support this argument as the higher EPEs frequency is noted over Northern, Interior and Southern regions during El Niño phase while Highland and Red Sea Coast regions receive more EPEs during the neutral phase. During the La Niña phase, all the regions of Saudi Arabia receive less EPEs. Overall about 37.44\% (26.3\%) of the total EPEs occurred during El Niño (La Niña phase). Similarly, about 44.6\% (31.5\%) of the total EPEs occur over Saudi Arabia during the positive (negative) CGT phase. Therefore, EPEs frequency over Saudi Arabia is enhanced (reduced) during the positive (negative) ENSO and CGT phases.

The composite analysis for EPEs during different ENSO phases also revealed the wave-like pattern similar to the CGT, with slight fluctuations in its intensity and position. During El Niño phase, the wave like pattern is stronger and shifted toward south as compared with La Niña phase. Consequently, the mid-latitude storm activity is enhanced (reduced) resulting in enhanced (reduced) precipitation and EPEs during these phases over the region. Moreover, the moisture incursion and convergence enhance over Northern, Interior and Southern regions from the Red Sea and the Arabian Sea during El Niño phase which results in increased EPEs frequency over the regions during the phase. During the La Niña phase, the moisture component from the Arabian Sea reduces significantly, which explains the reduced percentages of EPEs over all the regions of Saudi Arabia.

We also found that positive CGT phase is associated with warm ENSO (El Niño) phase while negative CGT phase has the association with cold ENSO (La Niña) phase. This association is through the upper atmospheric GPHs and wind anomalies generating suitable conditions for the occurrence of EPEs over Saudi Arabia, which is also confirmed by the observed EPEs statistics. We also found that El Niño, along with positive CGT phase, the EPEs frequency enhances over Saudi Arabia while it reduces in La Niña with negative CGT phase.

Further studies are required to examine the linkages between EPEs over Saudi Arabia and the other large scale forcings such as Indian Ocean Dipole (IOD), and Madden Julian Oscillation (MJO). In a subsequent study, we will examine these teleconnections in detail by performing the simulation experiments with the newly developed Saudi King Abdulaziz University (KAU) Coupled Global Climate Model (CGCM) (Almazroui et al., 2017).

\section{Acknowledgments}

The Author acknowledges the Deanship of Graduate Studies (DGS), Deanship of Scientific Research (DSR), and Center of Excellence for Climate Change Research (CECCR), Department of Meteorology, King Abdulaziz University, Jeddah for providing the financial and logistic support to conduct this study. The General Authority of Meteorology and Environmental Protection (GAMEP) for the provision of observed daily precipitation data used in this study is also acknowledged. The computational work is carried out on the Aziz Supercomputer at King Abdulaziz University High-Performance Computing Centre, Jeddah, Saudi Arabia (http://hpc.kau.edu.sa). Two anonymous reviewers are also acknowledged for their suggestions which improved the quality of the manuscript.

\section{Appendix A. Supplementary data}

Supplementary data to this article can be found online at https:// doi.org/10.1016/j.atmosres.2019.104655.

\section{References}

Abid, M.A., Kucharski, F., Almazroui, M., Kang, I.S., 2016. Interannual rainfall variability and ECMWF-Sys4-based predictability over the Arabian Peninsula winter monsoon region. Q. J. R. Meteorol. Soc. 142, 233-242. https://doi.org/10.1002/qj.2648. Abid, M.A., Almazroui, M., Kucharski, F., O'Brien, E., Yousef, A.E., 2018. ENSO relationship to summer rainfall variability and its potential predictability over Arabian Peninsula region. npj Clim. Atm. Sci. 1, 20171. https://doi.org/10.1038/s41612-0170003-7.

Agel, L., Barlow, M., Qian, J.-H., Colby, F., Douglas, E., Eichler, T., 2015. Climatology of Daily Precipitation and Extreme Precipitation events in the Northeast United States. J. Hydrometeorol. 16, 2537-2557. https://doi.org/10.1175/JHM-D-14-0147.1.

Alexander, L.V., Zhang, X., Peterson, T.C., Caesar, J., Gleason, B., Klein Tank, A.M.G., Haylock, M., Collins, D., Trewin, B., Rahimzadeh, F., Tagipour, A., Rupa Kumar, K., Revadekar, J., Griffiths, G., Vincent, L., Stephenson, D.B., Burn, J., Aguilar, E., Brunet, M., Taylor, M., New, M., Zhai, P., Rusticucci, M., Vazquez-Aguirre, J.L., 2006. Global observed changes in daily climate extremes of temperature and precipitation. J. Geophys. Res.-Atmos. 111. https://doi.org/10.1029/2005JD006290.

Almazroui, M., 2011a. Calibration of TRMM rainfall climatology over Saudi Arabia during 1998-2009. Atmos. Res. 99, 400-414. https://doi.org/10.1016/j.atmosres. 2010.11.006.

Almazroui, M., 2011b. Sensitivity of a regional climate model on the simulation of high intensity rainfall events over the Arabian Peninsula and around Jeddah (Saudi Arabia). Theor. Appl. Climatol. 104, 261-276. https://doi.org/10.1007/s00704-0100387-3.

Almazroui, M., 2012. The life cycle of extreme rainfall events over western Saudi Arabia simulated by a regional climate model: case study of November 1996. Atmósfera 25, 23-41.

Almazroui, M., Islam, M.N., Jones, P.D., Athar, H., Rahman, M.A., 2012a. Recent climate change in the Arabian Peninsula: seasonal rainfall and temperature climatology of Saudi Arabia for 1979-2009. Atmos. Res. https://doi.org/10.1016/j.atmosres.2012. 02.013 .

Almazroui, M., Nazrul Islam, M., Athar, H., Jones, P.D., Rahman, M.A., 2012b. Recent climate change in the Arabian Peninsula: annual rainfall and temperature analysis of Saudi Arabia for 1978-2009. Int. J. Climatol. https://doi.org/10.1002/joc.3446.

Almazroui, M., Abid, M.A., Athar, H., Islam, M.N., Ehsan, M.A., 2013. Interannual variability of rainfall over the Arabian Peninsula using the IPCC AR4 global climate models. Int. J. Climatol. 33, 2328-2340. https://doi.org/10.1002/joc.3600.

Almazroui, M., Dambul, R., Islam, M.N., Jones, P.D., 2015. Principal components-based regionalization of the Saudi Arabian climate. Int. J. Climatol. 35, 2555-2573. https:// doi.org/10.1002/joc.4139.

Almazroui, M., Kamil, S., Ammar, K., Keay, K., Alamoudi, A.O., 2016. Climatology of the 500-hPa mediterranean storms associated with Saudi Arabia wet season precipitation. Clim. Dyn. https://doi.org/10.1007/s00382-016-3011-0.

Almazroui, M., Tayeb, O., Mashat, A.S., Yousef, A., Al-Turki, Y.A., Abid, M.A., Bafail, A.O., Ehsan, M.A., Zahed, A., Rahman, M.A., Mohorji, A.M., Kang, I.-S., Noaman, A., Omar, M., Al-roqi, A.M., Ammar, K., Al-Ghamdi, A.S., Hussein, M.A.A., Katib, I., O’Brien, E., Aljohani, N.R., Islam, M.N., Alsaedi, A., Yang, Y.-M., Alkhalaf, A.K., Ismail, M., Mashat, A., Kucharski, F., Assiri, M., Ibrahim, S., Tippett, M., Rashid, I.U., Kamil, S., Alahmadi, A., Atif, R.M., Bajunaid, M.A., Hantoush, A.S., 2017. Saudi-KAU coupled global climate model: description and performance. Earth Syst. Environ. 1, 7. https://doi.org/10.1007/s41748-017-0009-7.

Almazroui, M., Alobaidi, M., Saeed, S., Mashat, A., Assiri, M., 2018. The possible impact of the circumglobal wave train on the wet season dust storm activity over the northern Arabian Peninsula. Clim. Dyn. https://doi.org/10.1007/s00382-0173747-1.

Almazroui, M., Rashid, I.U., Saeed, S., Islam, M.N., 2019. ENSO influence on summer temperature over Arabian Peninsula: role of mid-latitude circulation. Clim. Dyn. 1-16. https://doi.org/10.1007/s00382-019-04848-4.

Alsarmi, S.H., Washington, R., 2014. Changes in climate extremes in the Arabian Peninsula: analysis of daily data. Int. J. Climatol. 34, 1329-1345. https://doi.org/10. 1002/joc.3772.

Anagnostopoulou, C., Tolika, K., 2012. Extreme precipitation in Europe: Statistical threshold selection based on climatological criteria. Theor. Appl. Climatol. 107, 479-489. https://doi.org/10.1007/s00704-011-0487-8.

Athar, H., 2015. Teleconnections and variability in observed rainfall over Saudi Arabia during 1978-2010. Atmos. Sci. Lett. https://doi.org/10.1002/asl2.570.

Beniston, M., Stephenson, D.B., 2004. Extreme climatic events and their evolution under changing climatic conditions. Glob. Planet. Chang. 44, 1-9. https://doi.org/10.1016/ J.GLOPLACHA.2004.06.001.

Branstator, G., 2002. Circumglobal teleconnections, the jet stream waveguide, and the North Atlantic Oscillation. J. Clim. 15, 1893-1910. https://doi.org/10.1175/15200442(2002)015<1893:CTTJSW > 2.0.CO;2.

Casanueva, A., Rodríguez-Puebla, C., Frías, M.D., González-Reviriego, N., 2014. Variability of extreme precipitation over Europe and its relationships with teleconnection patterns. Hydrol. Earth Syst. Sci. https://doi.org/10.5194/hess-18-7092014.

Cayan, D.R., Redmond, K.T., Riddle, L.G., 1999. ENSO and hydrologic extremes in western North America. J. Clim. 12, 2881-2893 (ST-ENSO and hydrologic extremes in we. doi:10.1175/1520-0442(1999)012 < 2881:EAHEIT > 2.0.CO;2).

de Vries, A.J., Ouwersloot, H.G., Feldstein, S.B., Riemer, M., El Kenawy, A.M., McCabe, M.F., Lelieveld, J., 2018. Identification of tropical-extratropical interactions and extreme precipitation events in the middle east based on potential vorticity and moisture transport. J. Geophys. Res. Atmos. https://doi.org/10.1002/ 2017JD027587.

de Vries, A.J., Tyrlis, E., Edry, D., Krichak, S.O., Steil, B., Lelieveld, J., 2013. Extreme precipitation events in the middle east: dynamics of the active red sea trough. J. Geophys. Res. Atmos. https://doi.org/10.1002/jgrd.50569.

Dee, D.P., Uppala, S.M., Simmons, A.J., Berrisford, P., Poli, P., Kobayashi, S., Andrae, U., Balmaseda, M.A., Balsamo, G., Bauer, P., Bechtold, P., Beljaars, A.C.M., van de Berg, 
L., Bidlot, J., Bormann, N., Delsol, C., Dragani, R., Fuentes, M., Geer, A.J., Haimberger, L., Healy, S.B., Hersbach, H., Hólm, E.V., Isaksen, L., Kållberg, P., Köhler, M., Matricardi, M., Mcnally, A.P., Monge-Sanz, B.M., Morcrette, J.J., Park, B.K., Peubey, C., de Rosnay, P., Tavolato, C., Thépaut, J.N., Vitart, F., 2011. The ERAInterim reanalysis: configuration and performance of the data assimilation system. $\mathrm{Q}$. J. R. Meteorol. Soc. https://doi.org/10.1002/qj.828.

DeFlorio, M.J., Pierce, D.W., Cayan, D.R., Miller, A.J., 2013. Western U.S. extreme precipitation events and their relation to ENSO and PDO in CCSM4. J. Clim. 26, 4231-4243. https://doi.org/10.1175/JCLI-D-12-00257.1.

Deng, L., McCabe, M.F., Stenchikov, G., Evans, J.P., Kucera, P.A., 2015. Simulation of flash-flood-producing storm events in Saudi Arabia using the weather research and forecasting model*. J. Hydrometeorol. 16, 615-630. https://doi.org/10.1175/JHMD-14-0126.1.

Ding, Q., Wang, B., 2005. Circumglobal teleconnection in the Northern Hemisphere summer. J. Clim. https://doi.org/10.1175/JCLI3473.1.

Ding, Q., Wang, B., 2007. Intraseasonal teleconnection between the summer Eurasian wave train and the Indian Monsoon. J. Clim. https://doi.org/10.1175/JCLI4221.1.

Donat, M.G., Alexander, L.V., Yang, H., Durre, I., Vose, R., Dunn, R.J.H., Willett, K.M., Aguilar, E., Brunet, M., Caesar, J., Hewitson, B., Jack, C., Klein Tank, A.M.G., Kruger, A.C., Marengo, J., Peterson, T.C., Renom, M., Oria Rojas, C., Rusticucci, M., Salinger, J., Elrayah, A.S., Sekele, S.S., Srivastava, A.K., Trewin, B., Villarroel, C., Vincent, L.A., Zhai, P., Zhang, X., Kitching, S., 2013. Updated analyses of temperature and precipitation extreme indices since the beginning of the twentieth century: the HadEX2 dataset. J. Geophys. Res.-Atmos. https://doi.org/10.1002/jgrd.50150.

Donat, M.G., Peterson, T.C., Brunet, M., King, A.D., Almazroui, M., Kolli, R.K., Boucherf, D., Al-Mulla, A.Y., Nour, A.Y., Aly, A.A., Nada, T.A.A., Semawi, M.M., Al Dashti, H.A., Salhab, T.G., El Fadli, K.I., Muftah, M.K., Dah Eida, S., Badi, W., Driouech, F., El Rhaz, K., Abubaker, M.J.Y., Ghulam, A.S., Erayah, A.S., Mansour, M.B., Alabdouli, W.O., Al Dhanhani, J.S., Al Shekaili, M.N., 2014. Changes in extreme temperature and precipitation in the Arab region: long-term trends and variability related to ENSO and NAO. Int. J. Climatol. 34, 581-592. https://doi.org/10.1002/joc.3707.

Ehsan, M.A., Tippett, M.K., Almazroui, M., Ismail, M., Yousef, A., Kucharski, F., Omar, M., Hussein, M., Alkhalaf, A.A., 2017. Skill and predictability in multimodel ensemble forecasts for Northern Hemisphere regions with dominant winter precipitation. Clim. Dyn. 48, 3309-3324. https://doi.org/10.1007/s00382-016-3267-4.

Elquliti, S., Alfalatah, S.M., Alghamdi, M., Alrowaily, A., 2016. Impact analysis for flooding AREA, In SAUDI ARABIA. Int. J. Sci. Tech. Res. Eng. (IJSTRE) www.ijstre.com 1 (2), 1-7.

EM-DAT, C, 2012. The International Disaster Database. Centre for Research on the Epidemiology of Disasters.

Feldstein, S.B., Dayan, U., 2008. Circumglobal teleconnections and wave packets associated with Israeli winter precipitation. Q. J. R. Meteorol. Soc. https://doi.org/10. 1002/qj.225.

Gershunov, A., Barnett, T.P., 1998. ENSO influence on intraseasonal extreme rainfall and temperature frequencies in the contiguous united states: observations and model results. J. Clim. https://doi.org/10.1175/1520-0442(1998)011<1575:EIOIER>2.0. $\mathrm{CO} ; 2$.

Gimeno, L., Dominguez, F., Nieto, R., Trigo, R., Drumond, A., Reason, C., Taschetto, A., Ramos, A., Kumar, R., Marengo, J., 2016. Major mechanisms of atmospheric moisture transport and their role in extreme precipitation events. SSRN. https://doi.org/10. 1146/annurev-environ-110615-085558.

Grimm, A.M., Tedeschi, R.G., 2009. ENSO and extreme rainfall events in South America. J. Clim. https://doi.org/10.1175/2008JCLI2429.1.

Haggag, M., El-Badry, H., 2013. Mesoscale Numerical Study of Quasi-Stationary Convective System over Jeddah in November 2009. Atmos. Clim. Sci. 03, 73-86. https://doi.org/10.4236/acs.2013.31010.

Higgins, R.W., Schemm, J.K.E., Shi, W., Leetmaa, A., 2000. Extreme precipitation events in the Western United States related to tropical forcing. J. Clim. 13, 793-820. https:// doi.org/10.1175/1520-0442(2000)013<0793:EPEITW > 2.0.CO;2.

Huang, B., Thorne, P.W., Banzon, V.F., Boyer, T., Chepurin, G., Lawrimore, J.H., Menne, M.J., Smith, T.M., Vose, R.S., Zhang, H.M., 2017. Extended reconstructed Sea surface temperature, version 5 (ERSSTv5): upgrades, validations, and intercomparisons. J. Clim. 30, 8179-8205. https://doi.org/10.1175/JCLI-D-16-0836.1.

IPCC, 2007. Summary for policymakers. In: Climate Change 2007: The Physical Science Basis. Contribution of Working Group I to the Fourth Assessment Report of the Intergovernmental Panel on Climate Change, Fourth Assessment Report of the Intergovernmental Panel on Climate Change, https://doi.org/10.1038/nrc3183.

Kamil, S., Almazroui, M., Kucharski, F., Kang, I.-S., 2017. Multidecadal changes in the Relationship of storm Frequency over Euro-Mediterranean Region and ENSO during Boreal Winter. Earth Sys. Environ. 1, 6.

Kamil, S., Almazroui, M., Kang, I.-S., Hanif, M., Kucharski, F., Abid, M.A., Saeed, F., 2019. Long-term ENSO relationship to precipitation and storm frequency over western Himalaya-Karakoram-Hindukush region during the winter season. Clim. Dyn. 1-14. https://doi.org/10.1007/s00382-019-04859-1.

Kang, I.S., Rashid, I.U., Kucharski, F., Almazroui, M., Alkhalaf, A.K., 2015. Multidecadal changes in the relationship between ENSO and wet-season precipitation in the Arabian Peninsula. J. Clim. https://doi.org/10.1175/JCLI-D-14-00388.1.

Klein Tank, A.M.G., Können, G.P., 2003. Trends in Indices of daily temperature and precipitation extremes in Europe, 1946-99. J. Clim. https://doi.org/10.1175/15200442(2003) $016<3665$ :TIIODT > 2.0.CO;2.

Krichak, S.O., Breitgand, J.S., Feldstein, S.B., 2012. A conceptual model for the identification of active red sea trough synoptic events over the southeastern mediterranean. J. Appl. Meteorol. Climatol. https://doi.org/10.1175/JAMC-D-11-0223.1.

Kucharski, F., Abid, M.A., 2017. Interannual Variability of the Indian Monsoon and its Link to ENSO. https://doi.org/10.1093/ACREFORE/9780190228620.013.615.

Kucharski, F., Bracco, A., Yoo, J.H., Molteni, F., 2007. Low-frequency variability of the Indian monsoon-ENSO relationship and the tropical Atlantic: the "weakening" of the 1980s and 1990s. J. Clim. 20, 4255-4266. https://doi.org/10.1175/JCLI4254.1.

Lélé, M.I., Leslie, L.M., Lamb, P.J., 2015. Analysis of low-level atmospheric moisture transport associated with the West African monsoon. J. Clim. 28, 4414-4430. https:// doi.org/10.1175/JCLI-D-14-00746.1.

Liebmann, B., Smith, C., 1996. Description of a complete (Interpolated) outgoing longwave radiation dataset. Bull. Amer, Meteor. Soc. 77, 1275-1277.

Niranjan Kumar, K., Entekhabi, D., Molini, A., 2015. Hydrological extremes in hyperarid regions: a diagnostic characterization of intense precipitation over the Central Arabian Peninsula. J. Geophys. Res. https://doi.org/10.1002/2014JD022341.

Rasmusson, E.M., Carpenter, T.H., 1983. the relationship between eastern equatorial pacific sea surface temperatures and rainfall over India and Sri Lanka. Mon. Weather Rev. https://doi.org/10.1175/1520-0493(1983)111<0517:TRBEEP > 2.0.CO;2.

Ropelewski, C.F., Halpert, M.S., 1987. Global and regional scale precipitation patterns associated with the El Niño/Southern oscillation. Mon. Weather Rev. https://doi.org/ 10.1175/1520-0493(1987)115<1606:GARSPP > 2.0.CO;2.

Saeed, S., Almazroui, M., 2019. Impacts of mid-latitude circulation on winter precipitation over the Arabian Peninsula. Clim. Dyn. 1-12. https://doi.org/10.1007/s00382019-04862-6.

Saeed, S., Müller, W.A., Hagemann, S., Jacob, D., 2011. Circumglobal wave train and the summer monsoon over northwestern India and Pakistan: the explicit role of the surface heat low. Clim. Dyn. 37, 1045-1060. https://doi.org/10.1007/s00382-0100888-x.

Saeed, S., Van Lipzig, N., Müller, W.A., Saeed, F., Zanchettin, D., 2014. Influence of the circumglobal wave-train on European summer precipitation. Clim. Dyn. 43, 503-515. https://doi.org/10.1007/s00382-013-1871-0.

Seneviratne, S., Nicholls, N., Easterling, D., Goodess, C., Kanae, S., Kossin, J., Luo, Y., Marengo, J., McInnes, K., Rahimi, M., Reichstein, M., Sorteberg, A., Vera, C., Zhang, X., 2012. Changes in climate extremes and their impacts on the natural physical environment. In: Managing the Risk of Extreme Events and Disasters to Advance Climate Change Adaptation, https://doi.org/10.1017/CBO9781139177245.006.

Shimizu, M.H., Ambrizzi, T., Liebmann, B., 2017. Extreme precipitation events and their relationship with ENSO and MJO phases over northern South America. Int. J. Climatol. https://doi.org/10.1002/joc. 4893.

Sun, X., Renard, B., Thyer, M., Westra, S., Lang, M., 2015. A global analysis of the asymmetric effect of ENSO on extreme precipitation. J. Hydrol. 530, 51-65. https:// doi.org/10.1016/j.jhydrol.2015.09.016.

Tsvieli, Y., Zangvil, A., 2007. Synoptic climatological analysis of Red Sea trough and nonRed Sea trough rain situations over Israel. Adv. Geosci. https://doi.org/10.5194/ adgeo-12-137-2007.

Wang, C., Wang, L., 2018. Combined effects of synoptic-scale teleconnection patterns on summer precipitation in Southern China. Atmosphere. https://doi.org/10.3390/ atmos9040154.

Wang, N., Zhang, Y., 2015. Evolution of Eurasian teleconnection pattern and its relationship to climate anomalies in China. Clim. Dyn. https://doi.org/10.1007/ s00382-014-2171-z.

Wang, S.Y., Davies, R.E., Gillies, R.R., 2013. Identification of extreme precipitation threat across midlatitude regions based on short-wave circulations. J. Geophys. Res. Atmos. 118, 11059-11074. https://doi.org/10.1002/jgrd.50841.

Watanabe, M., 2004. Asian jet waveguide and a downstream extension of the North Atlantic Oscillation. J. Clim. https://doi.org/10.1175/JCLI-3228.1.

Wei, W., Shi, Z., Yang, X., Wei, Z., Liu, Y., Zhang, Z., Ge, G., Zhang, X., Guo, H., Zhang, K., Wang, B., 2017. Recent trends of extreme precipitation and their teleconnection with atmospheric circulation in the Beijing-Tianjin Sand source region, China, 1960-2014. Atmosphere 8, 1-18. https://doi.org/10.3390/atmos8050083.

Weir, J.B.D.V., 1960. Significance of the difference between two means when the population variances may be unequal. Nature 187, 438. https://doi.org/10.1038/ 187438a0.

Yadav, R.K., Yoo, J.H., Kucharski, F., Abid, M.A., 2010. Why is ENSO influencing Northwest India winter precipitation in recent decades? J. Clim. 23, 1979-1993. https://doi.org/10.1175/2009JCLI3202.1.

Zolina, O., Dufour, A., Gulev, S.K., Stenchikov, G., 2016. Regional hydrological cycle over the Red Sea in ERA-Interim. J. Hydrometeorol. 18, 65-83. https://doi.org/10.1175/ jhm-d-16-0048.1. 